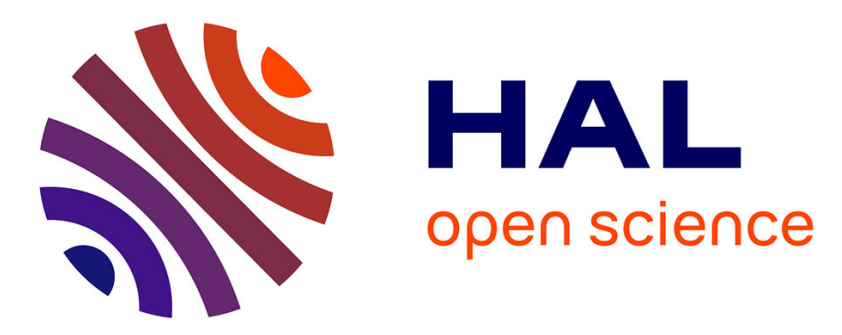

\title{
Size-dependent proton localization in hydrated uracil clusters: A joint experimental and theoretical study
}

Isabelle Braud, Sébastien Zamith, Jérôme Cuny, Linjie Zheng, Jean-Marc L'Hermite

\section{- To cite this version:}

Isabelle Braud, Sébastien Zamith, Jérôme Cuny, Linjie Zheng, Jean-Marc L'Hermite. Size-dependent proton localization in hydrated uracil clusters: A joint experimental and theoretical study. Journal of Chemical Physics, 2019, 150 (1), pp.014303. 10.1063/1.5044481 . hal-01973147

\section{HAL Id: hal-01973147 \\ https://hal.science/hal-01973147}

Submitted on 8 Jan 2019

HAL is a multi-disciplinary open access archive for the deposit and dissemination of scientific research documents, whether they are published or not. The documents may come from teaching and research institutions in France or abroad, or from public or private research centers.
L'archive ouverte pluridisciplinaire HAL, est destinée au dépôt et à la diffusion de documents scientifiques de niveau recherche, publiés ou non, émanant des établissements d'enseignement et de recherche français ou étrangers, des laboratoires publics ou privés. 


\section{PublishSige-Dependent Proton Localization in Hydrated Uracil Clusters: A Joint Experimental and Theoretical Study}

Isabelle Braud ${ }^{\dagger}$, Sébastien Zamith ${ }^{\dagger}$, Jérôme Cuny ${ }^{\ddagger}$, Linjie Zheng ${ }^{\ddagger}$, and Jean-Marc L'Hermite $^{\dagger}$

† Laboratoire Collisions Agrégats Réactivité (LCAR/IRSAMC) UMR5589, Université de Toulouse and CNRS, 118 Route de Narbonne, F-31062 Toulouse, France

* Laboratoire de Chimie et Physique Quantiques (LCPQ/IRSAMC) UMR5626, Université de Toulouse and CNRS, 118 Route de Narbonne, F-31062 Toulouse, France

E-mail: sebastien.zamith@irsamc.ups-tlse.fr

A collision-induced dissociation study of hydrated protonated uracil $\left(\mathrm{H}_{2} \mathrm{O}\right)_{\mathrm{n}=1-15} \mathrm{UH}^{+}$clusters is reported. The mass-selected clusters collide with water molecules and rare gases at a controlled center of mass collision energy. From these measurements, absolute fragmentation cross sections and branching ratios are extracted as a function of the uracil hydration. For small clusters, up to $n=4$, we observe that only neutral water molecules are evaporated upon collisions, whereas for larger clusters neutral uracil is also evaporated: this transition in the nature of the evaporation products is interpreted considering the lowest-energy isomers of each species that are obtained from a combination of density-functional based tight-binding (DFTB) and MP2 calculations. The simulations show that in $\left(\mathrm{H}_{2} \mathrm{O}\right)_{1-4} \mathrm{UH}^{+}$the proton is located on the uracil molecule or on a water molecule strongly bound to uracil whereas, in larger clusters, the proton is bound to water molecules far from uracil. This correlation between the structure of the low-energy isomers and the experimental fragmentation channel suggests that dissociation may occur in a very short time after collisions, so that energy has not enough time to be redistributed among all degrees of freedom and the ground-state geometry of the parent cluster partly determines the nature of the favored fragmentation channels. Of course, thermal dissociations originating from long lived, thus thermalized, collision complexes cannot be ruled out but they are not expected to play the major role since experimental results can be satisfactorily accounted for by assuming that the fragmentation processes are mainly impulsive. 


\section{INTRODUCTION}

Water is the natural medium of the biological molecules, and the process of hydration is of general interest to chemists and biologists. The study of mixed clusters composed of biological molecules with water is therefore a good workbench to observe how the properties of biological molecules change when going from isolated gas-phase to hydrated species.

One challenging question of great medical interest nowadays is the effect of radiation onto DNA and RNA molecules. The damages on these molecules can be directly caused by the radiations, or indirectly by secondary electrons created by the radiation. Uracil $\mathrm{C}_{4} \mathrm{H}_{4} \mathrm{~N}_{2} \mathrm{O}_{2}$ (U) is one of the four nucleobases of RNA that received attention concerning radiation damage. Charged uracil $\mathrm{UH}^{+}$can be formed by radiation damages and has thus deserved some attention [1]. One of the reasons for such degradation can, for example, be due to the interaction with slow electrons as shown by the pioneer work of Boudaiffa et al.[2]. Although several studies have been devoted to the effect of hydration on the electron affinity of DNA bases $[3,4,5,6]$, there is still much to be done to understand the role of aqueous environment on DNA and RNA.

Studying fragmentation of biomolecules through collision induced dissociation (CID) is helpful to understand reactivity and provide access to structural information [7]. Fragmentation of the bare protonated uracil molecule has already been performed under CID with tandem mass spectrometry $[8,9,10,11,12]$, but there are only few studies available concerning the effect of hydration on such 
Publishipirgess. Infrared photodissociation spectroscopy of singly hydrated protonated uracil [13] shows that the most stable tautomeric form of the neutral uracil (di-keto) differs from the most stable one for bare protonated uracil (keto-enol). Some theoretical studies report the structures taken by neutral microhydrated uracil, containing up to 15 water molecules $[14,15,16,17,18]$. However fragmentation studies of such species under CID conditions has not been reported so far.

We report in this paper both the results of CID experiments performed on hydrated protonated uracil species $\left(\mathrm{H}_{2} \mathrm{O}\right)_{n} \mathrm{UH}^{+}(\mathrm{n}=1-15)$ and theoretical calculations to determine their lowest-energy structures. In the latter case, we used a methodology combining density-functional based tightbinding (DFTB), for a rough exploration of the potential energy surfaces, and MP2 calculations for accurate characterization of low-lying isomers. In our experiments, the dissociation of mass selected hydrated protonated uracil clusters is induced by collisions with rare gas atoms. After the collisions, the remaining charged species, which have lost one or several neutral subunits, are detected. The resulting inter-molecular dissociation patterns of the $\left(\mathrm{H}_{2} \mathrm{O}\right)_{n} \mathrm{UH}^{+}$clusters show that below $\mathrm{n}=5$ only water molecules are evaporated whereas for $\mathrm{n} \geq 5$ a new fragmentation channel appears corresponding to the loss of neutral uracil.

The fragmentation can arise from two distinct mechanisms depending on the life time of the collision complex. On the one hand if fragmentation occurs in a very short time after collision, the dissociation is impulsive (or direct), which mean that molecules are ejected from a parent cluster whose structure is essentially unchanged before evaporation takes place. In this case, the ground state structure of the parent cluster obviously plays a major role in determining the fragmentation channels. On the other hand, in the case of long-lived collision complexes, the structure of the cluster can undergo structural reorganizations before evaporation and the role of the initial structure of the parent clusters is strongly reduced. 
Publishing $/$ FTB/MP2 calculations demonstrate that there is a direct correlation between the location of the excess proton in the lowest-energy isomer of a considered cluster and the fragmentation channel it undergoes. This suggests that direct dissociation upon collision is responsible for the appearance of neutral uracil from $n=5$ as statistical dissociation would favor protonation of the uracil. However, an accurate measure of the relative contribution of statistical versus direct dissociation cannot be determined.

Section II of this paper describes the experimental set-up used to determine fragments branching ratios and fragmentation cross sections. The computational method used to determine the lowest-energy structures of hydrated protonated uracil clusters is described in section III. In section IV are reported the experimental cross sections and the fragmentation branching ratios of hydrated protonated uracil clusters. Finally, in section V the calculated structures of mixed uracilwater clusters are presented and the experimental results are discussed in the light of these structures. The main outcomes and perspectives are summarized in the conclusion.

\section{EXPERIMENTAL SET-UP}

Our experimental set-up enables collisions at a controlled kinetic energy between the molecules of a vapor and mass-selected thermalized charged clusters. It has been described in detail elsewhere [19]. Here we remind of the main stages. Charged clusters are produced in a gas aggregation source [20]. A flow of helium carrier gas and water vapor enters the source in a cell where uracil in solid form (Alpha Aesar, 99\%) is heated at $378 \mathrm{~K}$ to get a vapor pressure of about $6.6 \times 10^{-2}$ mbar [21]. A miniature electron gun located at the cell exit allows to ionize the clusters in the source. The typical kinetic energy of the electrons is $100 \mathrm{eV}$. The clusters formed in the 
Publishsingce at the temperature of liquid nitrogen are carried out of the source by the helium gas flow. The produced clusters then enter the thermalization chamber where tens of thousands collisions between the helium gas and the clusters cool them down to the helium gas temperature. A thermalization temperature of $25 \mathrm{~K}$ is obtained by cooling the thermalization chamber with a closed cycle helium cryostat. This low temperature reduces the amount of internal energy prior to collision compared to experiments usually performed at room temperature. For instance, using the harmonic frequencies $\omega_{\mathrm{i}}$ calculated for the neutral uracil [22], its internal energy Eint is estimated by:

$$
\sum_{i} \frac{\hbar \omega_{i}}{\mathrm{e}^{\hbar \omega_{i} / k_{B} T}-1}
$$

At $25 \mathrm{~K}$, the internal energy of uracil molecule is about $8 \mu \mathrm{eV}$, only the lowest-energy isomers are thus expected to subsequently undergo collision with the target species.

After the thermalization stage, the clusters then enter the high vacuum part of the experiment where an original time of flight device using electrostatic pulses applied to electrodes enables mass-selection and slowing down to a controlled kinetic energy. Laboratory frame collision energies, ranging from 54 to $145 \mathrm{eV}$, are measured by time of flight measurements [19]. In the present work the corresponding center of mass $(\mathrm{CM})$ collision energy is kept constant at $7.2 \mathrm{eV}$. This energy is chosen high enough so that a large number of fragmentation channels are explored.

The clusters cross the collision cell in free flight where they can collide with the molecules or

atoms of a vapor at $300 \mathrm{~K}$ whose pressure is controlled. The pressure in the cell is measured with a mechanical vacuum gauge (Leybold Ceravac CTR 91). The collision products are then mass 
Publishimgilyzed by a reflectron time-of-flight mass spectrometer and detected using micro channel plates. At that stage, it is worth pointing out that an accurate picture of the collision and subsequent fragmentation mechanism cannot be obtained from the present experimental set-up and we are not able to distinguish between direct dissociation and statistical evaporation.

Several target atoms or molecules $\mathrm{M}$ were introduced in the collision cell. We have performed experiments with $\mathrm{M}=\mathrm{H}_{2} \mathrm{O}, \mathrm{D}_{2} \mathrm{O}$, Ne and Ar. We find essentially the same results whatever the nature of $\mathrm{M}$, and in order to keep things clearer, we only present and discuss results obtained with $\mathrm{Ne}$ in this paper.

Figure 1: Time of flight of mass spectrum obtained by colliding $\left(\mathrm{H}_{2} \mathrm{O}\right)_{7} \mathrm{UH}^{+}$with $\mathrm{Ne}$ at $7.2 \mathrm{eV}$ center of mass collision energy ( $93.5 \mathrm{eV}$ in the laboratory frame). 
Publishing gigure 1 shows a typical fragmentation mass spectrum obtained here by colliding $\left(\mathrm{H}_{2} \mathrm{O}\right)_{\mathrm{n}=7} \mathrm{UH}^{+}$ with Neon at a CM collision energy of $7.2 \mathrm{eV}$. The more intense peak on the right comes from the parent cluster $\left(\mathrm{H}_{2} \mathrm{O}\right)_{n=7} \mathrm{UH}^{+}$, the next 7 peaks at the left of the parent peak correspond to the loss of 1 to 7 water molecules and the next 5 peaks to the left results from the evaporation of the uracil molecule and several water molecules. This figure is obtained at the highest pressure explored in the present experiments. For such a pressure multiple collisions are no longer negligible, thus allowing the evaporation of all water molecules. This is still true for the largest size investigated here, namely $n=15$.

From the mass spectrum of the collision products, the branching ratios (BR) of the different charged fragments can be determined. The branching ratio corresponds to the intensity of a specific fragment over the total intensity of fragments. It is important to notice that the fragments considered here are the charged ones.

The total fragmentation cross-section can be deduced from the mass spectrum as:

$$
\sigma_{T O T}=-\frac{\ln \left(\frac{I}{I_{0}}\right)}{\rho L_{c e l}}
$$

with:

$I$ : The number of clusters that have crossed the cell without undergoing any fragmentation;

$I_{0}:$ The total number of clusters that have crossed the cell ;

$\rho:$ The density of the vapor in the collision cell ;

Lcel: The length of the collision cell, namely $5 \mathrm{~cm}$ here ; 
Publishing collision cell as a function of the pressure in the collision cell. Figure 2 gives an example of the evolution of $-\ln \left(I / I_{0}\right)$ as a function of the product $\rho L_{c e l}$. The linearity of the curve presented in figure 2 ensures that a single collision is sufficient to induce the fragmentation of the parent cluster.

The fragmentation cross-section for a specific channel $i$ is then given by

$$
\sigma_{i}=B R_{i} \sigma_{T O T}
$$

where $B R_{i}$ is the branching ratio for channel $i$. In our study we will be interested in two specific channels. Channel 1 corresponds to the loss of only neutral water molecules whereas channel 2 corresponds to the loss of neutral uracil and one or several water molecules:

Channel 1: $\left(\mathrm{H}_{2} \mathrm{O}\right)_{\mathrm{n}} \mathrm{UH}^{+} \rightarrow\left(\mathrm{H}_{2} \mathrm{O}\right)_{\mathrm{n}-\mathrm{x}} \mathrm{UH}^{+}+\mathrm{xH}_{2} \mathrm{O}$
Channel 2: $\left(\mathrm{H}_{2} \mathrm{O}\right)_{\mathrm{n}} \mathrm{UH}^{+} \rightarrow\left(\mathrm{H}_{2} \mathrm{O}\right)_{\mathrm{n}-\mathrm{x}} \mathrm{H}^{+}+\mathrm{x} \mathrm{H}_{2} \mathrm{O}+\mathrm{U}$ 


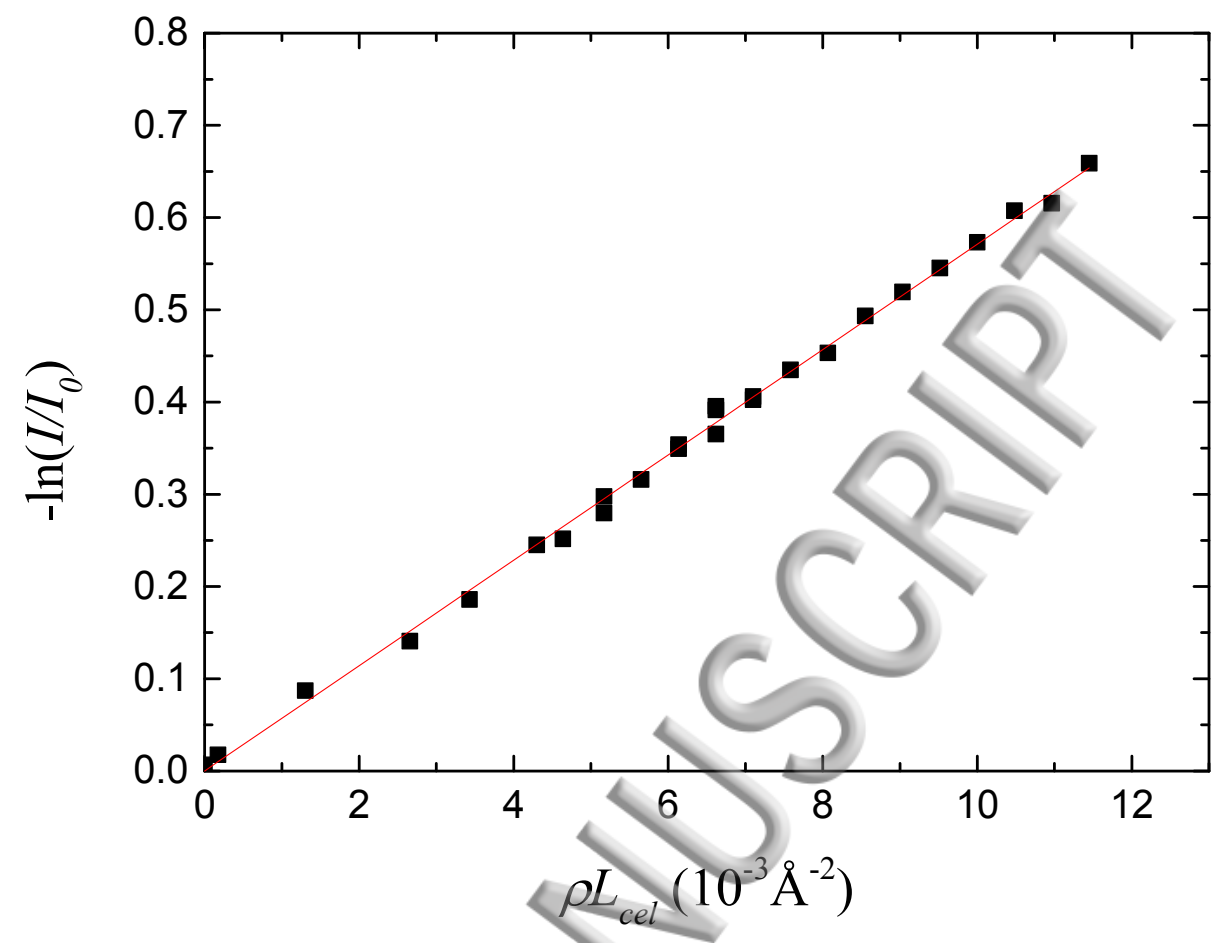

Figure 2: Extraction of the fragmentation cross section from experimental data using relation (2) in the case of $\left(\mathrm{H}_{2} \mathrm{O}\right)_{7} \mathrm{UH}^{+}$colliding with Neon at $7.2 \mathrm{eV}$ center of mass collision energy $(93.5 \mathrm{eV}$ in the laboratory frame).

Branching ratios are also determined by varying the collision cell pressure. The branching ratios for channel 1 and 2 are defined as follows:

$$
B R_{i}=\frac{I_{i}}{\sum_{i} I_{i}}
$$

Since $\sum_{i} I_{i}=I_{0}-I$ and using eq. (2), we have : 


$$
\frac{I_{i}}{I_{0}}=B R_{i}\left(1-\mathrm{e}^{-\rho L_{c e l} \sigma_{T O T}}\right)
$$

From relation (6), the branching ratios $B R_{i}$ are obtained as the slope of a linear fit of $I_{i} / I_{0}$ plotted as a function of $\left(1-\exp \left(-\rho L_{c e l} \sigma_{T O T}\right)\right)$, as exemplified in/Figure 3 in the case of $\left(\mathrm{H}_{2} \mathrm{O}\right)_{7} \mathrm{UH}^{+}$colliding with $\mathrm{Ne}$ atoms. Again the linearity of the curves suggests that single collision events are the predominant processes in our experiment. Indeed if two or more collisions were needed to induce fragmentations, this would lead to a non linear evolution with pressure. We do see such an effect for the largest sizes, $\mathrm{n}=10-15$, for which we took only low pressure points to determine the branching ratio. However, $7.2 \mathrm{eV}$ is only a low estimate of the energy deposited in the clusters.

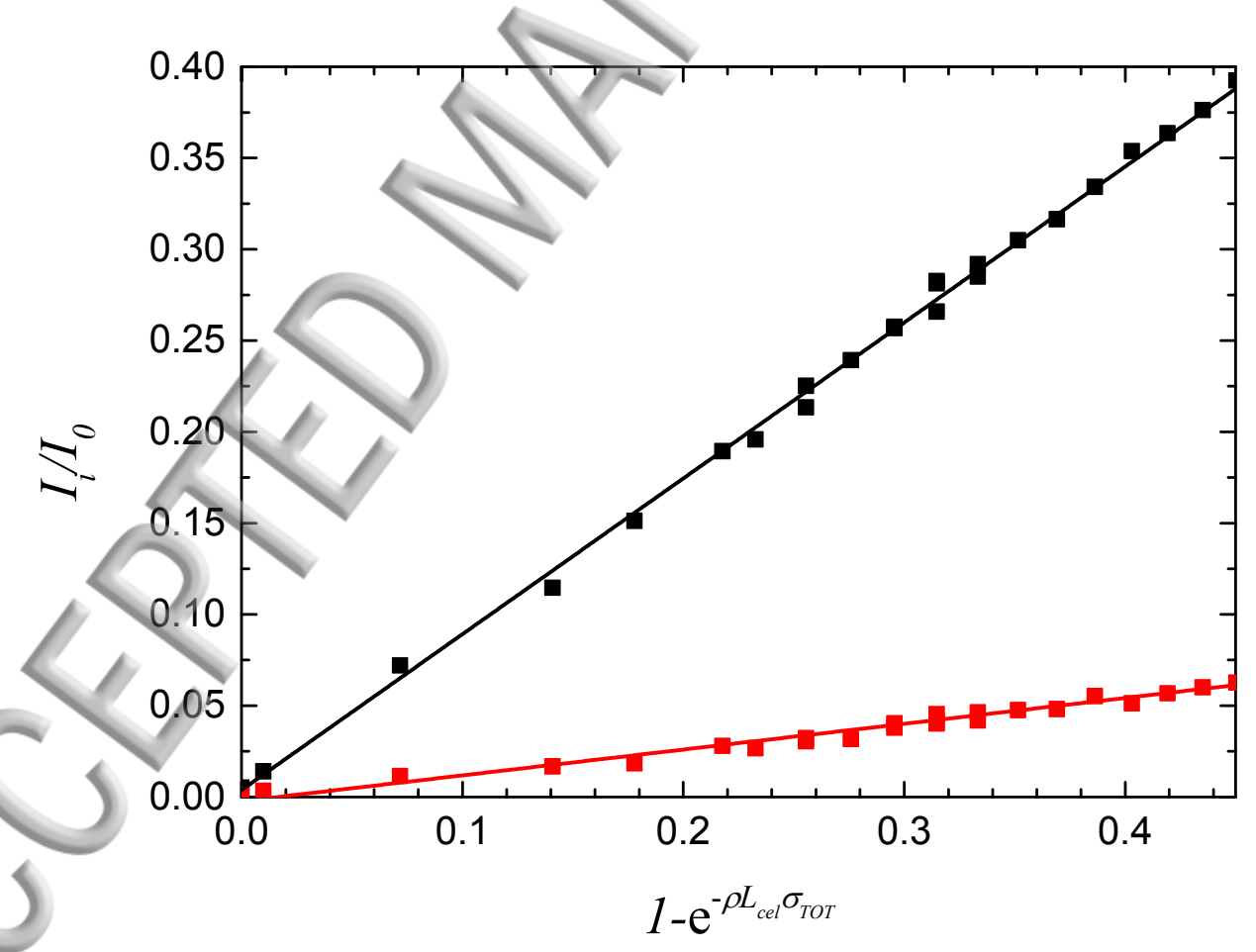

Figure 3: Determination of the branching ratios $B R i$ from the slope of linear fits (full lines) of the experimental data (squares) using relation (6) in the case of $\left(\mathrm{H}_{2} \mathrm{O}\right)_{7} \mathrm{UH}^{+}$colliding with $\mathrm{Ne}$ at $7.2 \mathrm{eV}$ center of mass collision energy ( $93.5 \mathrm{eV}$ in the laboratory frame). The black curves correspond to the 
Publishingevaporation of water molecules only (Channel 1 in relation (4)), and the red curves to the evaporation of uracil and water molecules (Channel 2 in relation (4)).

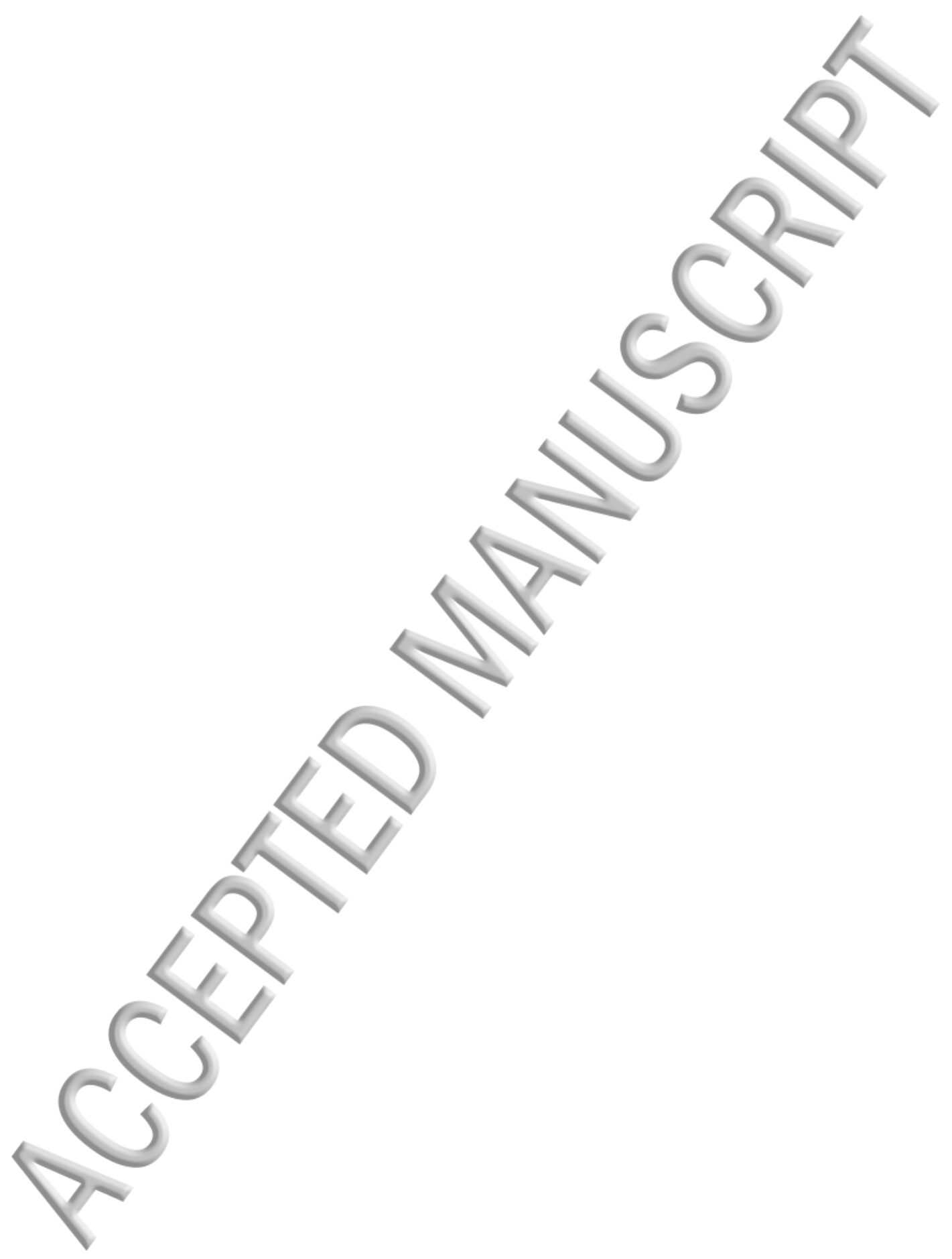


III. COMPUTATIONAL METHOD

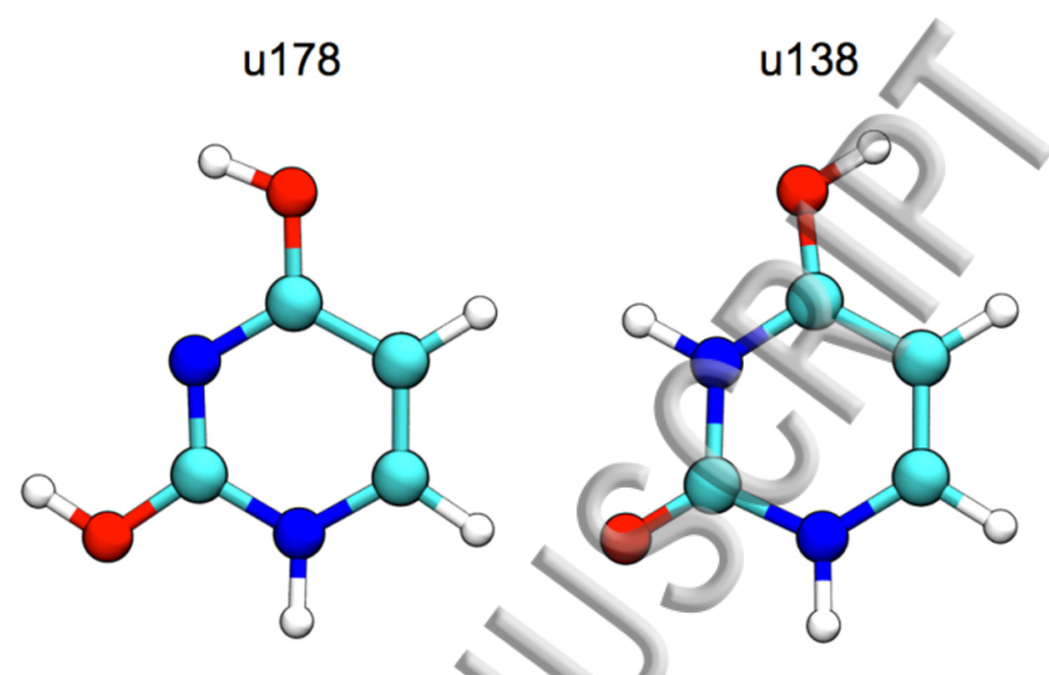

Figure 4: Structure of the two protonated uracil isomers, u178 (ketoenol form) and u138 (di-keto form), used as initial conditions in the PTMD simulations. See reference [31] for the isomer numbering.

To determine the lowest-energy isomers of the $\mathrm{U}\left(\mathrm{H}_{2} \mathrm{O}\right)_{\mathrm{n}} \mathrm{H}^{+}$clusters $(\mathrm{n}=1-7)$, we applied a twostep theoretical approach. First, to roughly explore the potential energy surfaces (PES), we conducted parallel-tempering molecular dynamics (PTMD) [23] simulations in combination with a self-consistent-charge density-functional based tight-binding (SCC-DFTB) [24] description of the energies and gradients. In the PTMD algorithm, we used 40 replicas with temperatures going linearly from 50 to $350 \mathrm{~K}$. All the trajectories were $4 \mathrm{~ns}$ long, and the integration time step was 0.5 fs. We found that a reasonable time interval for the PT exchanges was 2.5 ps. We used a NoséHoover chain of five thermostats with frequencies of $800 \mathrm{~cm}^{-1}$ to achieve an exploration in the canonical ensemble [25]. The SCC-DFTB calculations were performed with the mio-set for SlaterKoster tables of integrals and repulsive interactions [26]. To improve the description of 
Publishintegrnolecular interactions, we used the class IV/charge model 3 (CM3) [27] charges instead of the original Mulliken charges as well as empirical terms to describe dispersion interactions [28]. For the parametrization of the CM3 charges, we used the DoH parametrization proposed by Simon and co-workers (i.e. $\mathrm{D}_{\mathrm{oH}}=0.129$ ) [29], while all other values were set equal to 0, which corresponds to a Mulliken evaluation of the charges. All SCC-DFTB calculations were performed with the deMonNano code [30]. To avoid any spurious influence of the initial conditions on the PES exploration, three distinct PTMD simulations were carried out. In each one, a distinct initial proton location was set: on the uracil in two cases and on the water molecules in the other one. In the former case, the u178 and u138 isomers of $\mathrm{UH}^{+}$were used as initial geometries (see reference [31] for the isomer numbering and Figure 4 for a representation of those isomers), corresponding respectively to the keto-enol and the di-keto form. 600 geometries per temperature were randomly selected along each PTMD simulation for subsequent geometry optimization which leads to 72000 SCC-DFTB optimized structures for each cluster. The structures were sorted in ascending energy order and identical isomers were discarded. 9, 23, 46, 31, 38, 45 and 63 structures were then selected for $\mathrm{U}\left(\mathrm{H}_{2} \mathrm{O}\right) \mathrm{H}^{+}, \mathrm{U}\left(\mathrm{H}_{2} \mathrm{O}\right)_{2} \mathrm{H}^{+}, \mathrm{U}\left(\mathrm{H}_{2} \mathrm{O}\right)_{3} \mathrm{H}^{+}, \mathrm{U}\left(\mathrm{H}_{2} \mathrm{O}\right)_{4} \mathrm{H}^{+}, \mathrm{U}\left(\mathrm{H}_{2} \mathrm{O}\right)_{5} \mathrm{H}^{+}, \mathrm{U}\left(\mathrm{H}_{2} \mathrm{O}\right)_{6} \mathrm{H}^{+}$and $\mathrm{U}\left(\mathrm{H}_{2} \mathrm{O}\right)_{7} \mathrm{H}^{+}$, respectively, to perform geometry optimizations at the MP2 level of theory in combination with an all-electron Def2TZVP basis-set, [32,33] a tight criteria for geometry convergence and an ultrafine grid for the numerical integration. MP2 calculations were performed with the Gaussian 09 package [34]. 
FRAGMENTATION OF HYDRATED URACIL CLUSTERS: EXPERIMENTAL RESULTS

\section{A. Fragmentation cross section}

The total fragmentation cross sections of mixed clusters $\mathrm{U}\left(\mathrm{H}_{2} \mathrm{O}\right)_{\mathrm{n}-1} \mathrm{H}^{+}$, pure water clusters $\left(\mathrm{H}_{2} \mathrm{O}\right)_{\mathrm{n}=2-6} \mathrm{H}^{+} \quad$ [35] and deuterated water clusters $\left(\mathrm{D}_{2} \mathrm{O}\right)_{\mathrm{n}=5,10} \mathrm{H}^{+}[36]$ are plotted in Figure 5 as a function of the cluster size $\mathrm{n}$ (here $\mathrm{n}$ stands for the total number of molecules in the cluster including, when appropriate, the uracil molecule). Different target molecules or atoms were used in these experiments: Water molecules or Neon atoms in our experiments, Xenon atoms in Dalleska's experiments.

These experimental data are compared to the geometrical (i.e. hard sphere) cross sections given by:

$$
\sigma_{g e o}=\pi\left(\left[n_{w} \times r_{w}^{3}+n_{U} r_{U}^{3}\right]^{1 / 3}+r_{T}\right)^{2}
$$

Where $n_{w}$ is the number of water molecules, $n_{U}$ the number of uracil molecules ( $n_{U}=0$ or 1 in the present study), $r_{w}, r_{U}$ and $r_{T}$ are the molecular radii of water, uracil and of the target atom or molecule, respectively. The molecular radii are deduced from macroscopic densities that gives $r_{U}$ $=3.2 \AA[37], r_{w}=1.98 \AA$. The radii of rare gas target atoms are taken as their Van der Waals radii $r_{N e}=1.54 \AA$ and $r_{x e}=2.16 \AA$

The main differences between the curves in Figure 5 can be rationalized as follows: The larger the size of the target atom (or molecule), the larger the fragmentation cross section. The experimental fragmentation cross sections of mixed clusters $\mathrm{U}\left(\mathrm{H}_{2} \mathrm{O}\right)_{\mathrm{n}-1} \mathrm{H}^{+}$colliding with water molecules are larger than the values obtained for collisions with Ne atoms. In the same vein, for a given number of molecules in the cluster the cross section is larger for clusters containing uracil.

The overall trend of all curves in Figure 5 is the same: The fragmentation cross sections increase with the size and seem to tend towards the geometrical one. The cross sections measured 
Publishfing water clusters at a similar collision energy [36]. For mixed clusters, fragmentation cross sections are systematically larger than for pure water clusters by an amount of the same magnitude as the one predicted by the geometrical cross sections.

The fragmentation cross sections obtained by Dalleska and coworkers [35] for protonated water clusters are within our error bars for $n=5,6$ and about a factor of 2 lower for $n=3,4$. However their cross-section is notably lower for $\left(\mathrm{H}_{2} \mathrm{O}\right)_{2} \mathrm{H}^{+}$as compared to our measurement for $\mathrm{U}\left(\mathrm{H}_{2} \mathrm{O}\right) \mathrm{H}^{+}$. This difference may be explained by the fact that $\mathrm{UH}^{+}$forms a weaker bond with water than $\mathrm{H}_{3} \mathrm{O}^{+}$ does. Indeed the dissociation energy $\mathrm{D}\left[\mathrm{H}_{3} \mathrm{O}^{+}-\mathrm{H}_{2} \mathrm{O}\right]$ is $1.35 \mathrm{eV}[35,38]$ whereas the value for $\mathrm{D}\left[\mathrm{UH}^{+}-\mathrm{H}_{2} \mathrm{O}\right]$ is estimated between $0.54 \mathrm{eV}$ [1] and $0.73 \mathrm{eV}$ [13]. The same behavior is observed for $n=3$, the dissociation energies are $\mathrm{D}\left[\left(\mathrm{H}_{2} \mathrm{O}\right)_{2} \mathrm{H}^{+}-\mathrm{H}_{2} \mathrm{O}\right]=0.86 \mathrm{eV}[35,38]>\mathrm{D}\left[\mathrm{U}\left(\mathrm{H}_{2} \mathrm{O}\right)^{+}-\mathrm{H}_{2} \mathrm{O}\right]=$ $0.49 \mathrm{eV}[1]$. Hence the dissociation of water molecules is more favored in the mixed cluster than in the pure water clusters. 


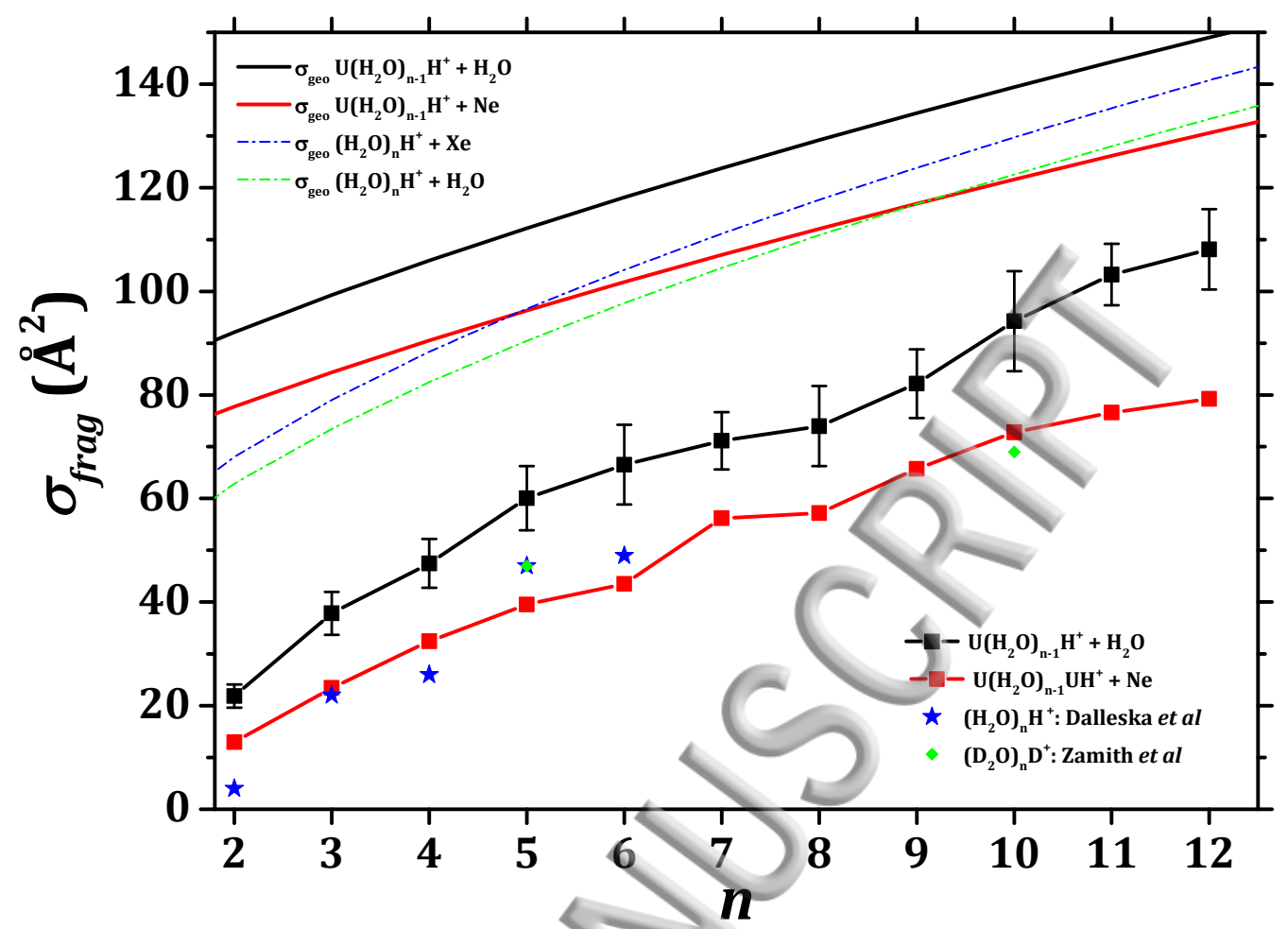

Figure 5: Fragmentation cross sections of mixed clusters $\mathrm{U}\left(\mathrm{H}_{2} \mathrm{O}\right)_{\mathrm{n}-1} \mathrm{H}^{+}$at a collision energy of $7.2 \mathrm{eV}$ plotted as a function of the total number n of molecules in the clusters (including uracil). Experimental results [and geometrical cross sections] are shown for collision with $\mathrm{H}_{2} \mathrm{O}$ (black squares [black full line]) and $\mathrm{Ne}$ (red squares [red full line]). The results of Dalleska et al. [35] (using Xe target atoms) on pure protonated water clusters $\left(\mathrm{H}_{2} \mathrm{O}\right)_{\mathrm{n}=2-6} \mathrm{H}^{+}$(blue stars) and of Zamith et al. [36] (using water target molecules) on deuterated water clusters $\left(\mathrm{D}_{2} \mathrm{O}\right)_{\mathrm{n}=5,10} \mathrm{H}^{+}$(green full circles) are also shown. The geometrical collision cross sections of water clusters (blue dashed line) in collision with Xe atoms (blue dash-dotted line) and water molecules (green dash-dotted line) are also plotted. Error bars represent one standard deviation.

\section{B. Inter-molecular fragmentation}

The branching ratios for the different dissociation channels (see relation (4)) of hydrated uracil are determined for clusters containing one uracil molecule and from 1 to 15 water molecules. The 
Publishfiggine 6 shows the percentage of the fragments that have lost a uracil neutral molecule, ie $\frac{B R_{2}}{B R_{1}+B R_{2}} \times 100$, plotted as a function of the number of water molecules in the parent cluster. It shows that in the mixed cluster with a small number of water molecules, almost no neutral uracil is evaporated. From $n=5$ and more clearly from $n=6$, the loss of neutral uracil molecule increases up to about $20 \%$ for $\mathrm{U}\left(\mathrm{H}_{2} \mathrm{O}\right){ }_{9} \mathrm{H}^{+}$.

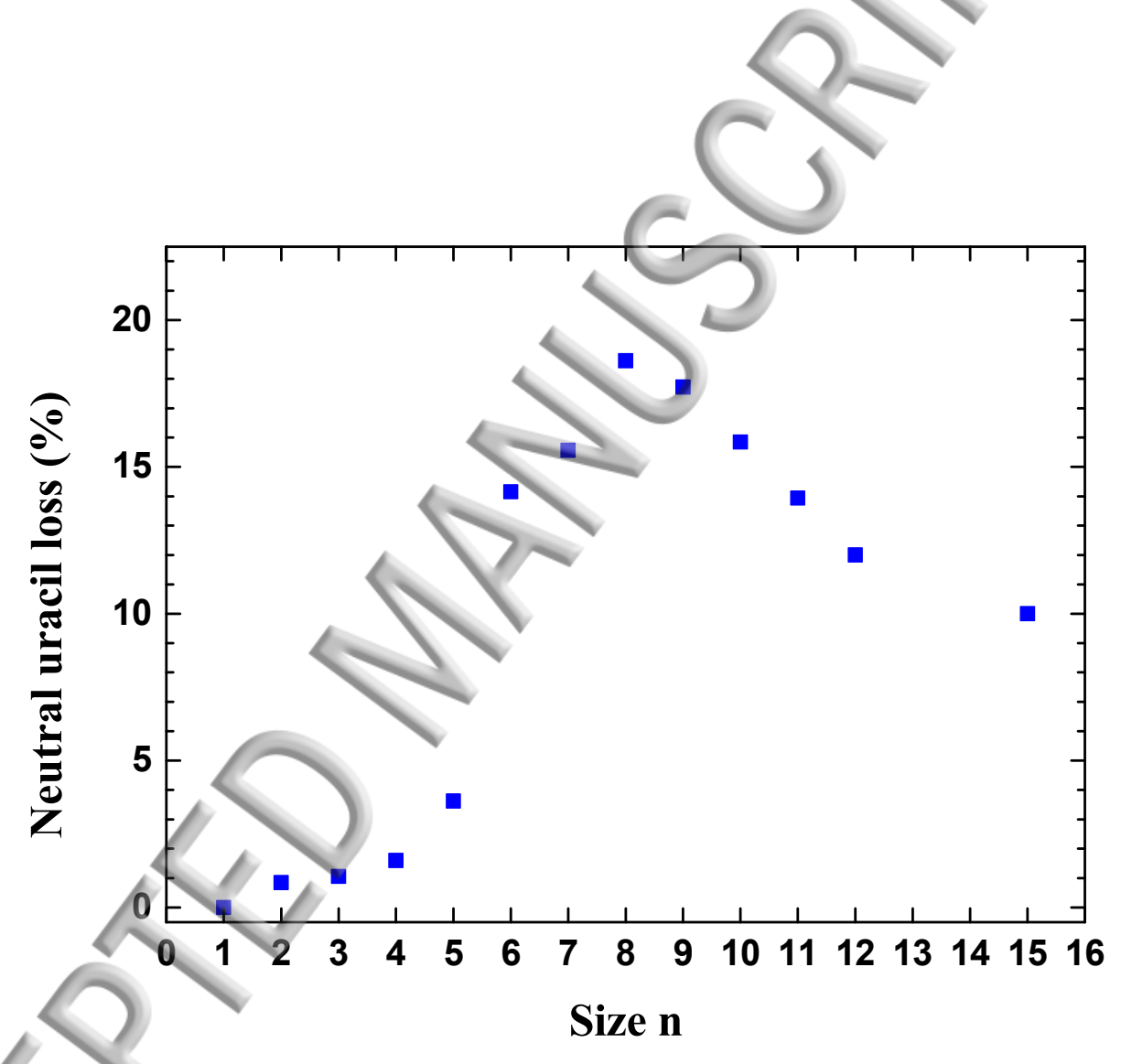

Figure 6: Proportion of neutral uracil molecule loss plotted as a function of the number $n$ of water molecules in the parent cluster $\mathrm{U}\left(\mathrm{H}_{2} \mathrm{O}\right)_{\mathrm{n}} \mathrm{H}^{+}$. Results obtained for collisions with $\mathrm{Ne}$ atoms at $7.2 \mathrm{eV} \mathrm{CM}$ collision energy. 
Publishingts stated above, both statistical and direct fragmentation processes can occur upon collision. In the former case collision energy is transferred to the parent cluster and is redistributed among all degrees of freedom. This is a slow process and the structures involved during the fragmentation are no longer the lowest-energy isomer. Furthermore, the excess proton can also diffuse in the structure and, for instance, re-combine with the uracil. In the latter case, dissociation is fast upon collision and the energy cannot be statistically redistributed among all degrees of freedom. We thus assume in that case that the nature of the collision products is partly determined by the nature of the lowestenergy isomers of parent clusters and especially by the location of the excess proton in the structure. In figure 6, we focus on the loss of the neutral uracil molecule in the detected fragments since it indicates where the proton lies after collision, namely on the uracil or on a water cluster. A transition in the nature of fragmentation product is clearly seen from $n=5-6$. To account for this transition we consider that evaporation originates from a direct fragmentation process. A short discussion about the implications of possible structural rearrangement prior to dissociation, which occurs in a statistical process, will be provided in section $\mathrm{V}$.

The relative proton affinities of each component of the mixed clusters gives a first estimate of which molecule - uracil or water - is more likely to carry the positive charge prior to collisions. Experimentally, the gas phase proton affinity of uracil is bracketed to $9 \pm 0.12 \mathrm{eV}$ [39]. For the water molecule, an experimental value for the proton affinity [40] is reported at $7.31 \mathrm{eV}$ and a theoretical one [41] at $7.5 \mathrm{eV}$. These last two works also show that the proton affinity of water clusters increases with their size [41]. We report in Figure 7 the proton affinities extracted from the different works for the uracil molecule and for water clusters as a function of the number of water molecules. 


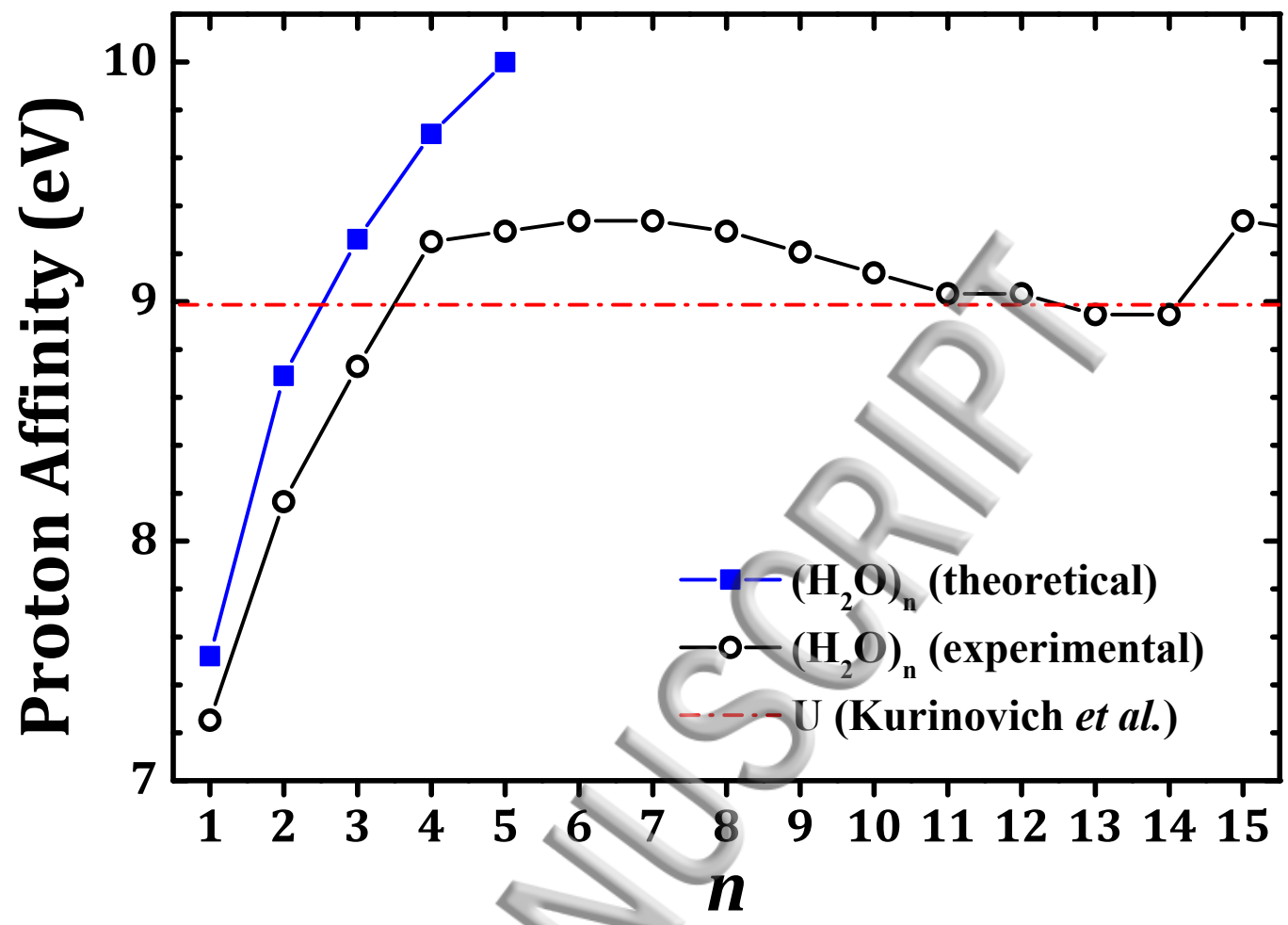

Figure 7: Proton affinities of the water clusters as a function of the number of water molecules $n$. Proton affinities are taken from [40] (black open circles) and from [41] (blue squares). The value of the proton affinity of uracil is also plotted (red dot dashed line [39]).

The proton affinity of uracil $\mathrm{PA}[\mathrm{U}]$ is hence larger than the one of water monomer $\mathrm{PA}\left[\mathrm{H}_{2} \mathrm{O}\right]$. Thus, for the mono-hydrated uracil, from the energetic point of view, the proton is on the uracil molecule and the only observed fragments are indeed protonated uracil molecules. Moreover, an experimental work [13] confirms that there is no proton transfer from the uracil to the water molecule in mono-hydrated clusters. Proton affinity of the uracil molecule is also larger than that of the water dimer, or even the trimer: $\mathrm{PA}[\mathrm{U}]>\mathrm{PA}\left[\left(\mathrm{H}_{2} \mathrm{O}\right)_{n}\right], n=2$ or 3 depending on the considered data for water. This is still consistent with our experimental observation of no neutral uracil molecule loss for $n=2$ and 3. However from the PA values one would predict that the appearance 
Publishing gieutral uracil should occur for $n \approx 3-4$. For instance for $n=4$, assuming a statistical fragmentation for which the end products energies are expected to be of relevance, the channel $\mathrm{U}+$ $\left(\mathrm{H}_{2} \mathrm{O}\right)_{4} \mathrm{H}^{+}$is energetically favorable. If one now assumes a direct dissociation, where the parent protonation state remains unchanged, one also expects that neutral uracil evaporates. However, experimentally, for $n=4$ no neutral uracil evaporation is observed. The loss of neutral uracil starts at $n=5$ and becomes significant only at $n=6$.

This analysis based on PA is however quite crude. Indeed, it assumes that the mixed cluster would be composed of a uracil molecule attached to an-intact water cluster. However, one expects that the hydration of uracil may be more complicated than this simple picture. The uracil hydration is explored theoretically in the next section in order to determine the proton location more realistically.

Finally, we note that we have a maximum of only about $20 \%$ of neutral uracil loss upon collisions with Neon atoms. For all sizes, the main fragmentation channel remains the loss of neutral water molecules. As the size increases, the proportion of neutral uracil evaporation even decreases. This feature may be explained by a simple entropic effect : The dissociation energy of a water molecule is very close to the dissociation energy of uracil (about $0.5 \mathrm{eV}$ in both cases), thus their evaporation probability is expected to be comparable. Therefore the weak evaporation probability of uracil is merely correlated to the larger number of water molecules likely to evaporate as the cluster size increases. 


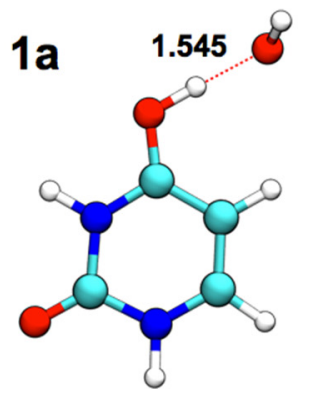

Erel

0.0

Ebind

$-22.4$

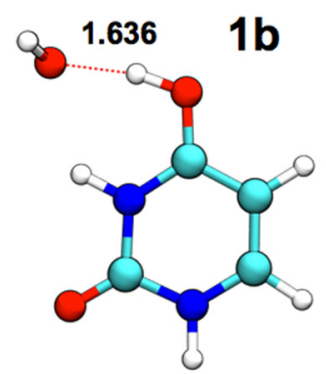

$E_{\text {rel }}$

Ebind
0.7

$-24.6$

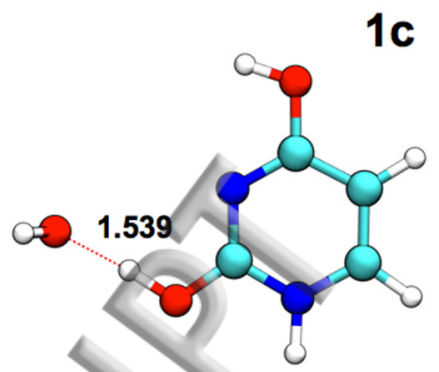

1.1

$-18.8$

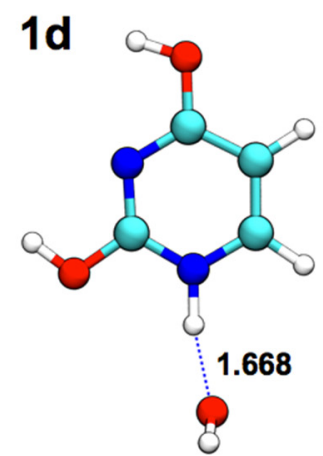

$E_{\text {rel }}$

Ebind $\quad-18.0$

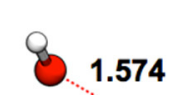

1.574

$1 e$
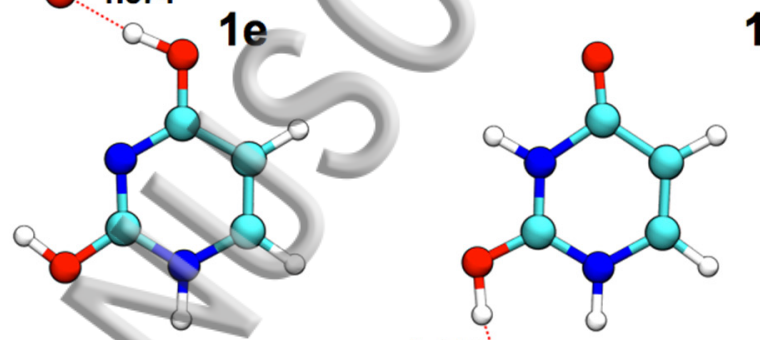

$1 f$

Figure 8: $\left.\mathrm{U}_{(} \mathrm{H}_{2} \mathrm{O}\right) \mathrm{H}^{+}$lowest-energy structures obtained at the MP2/Def2TZVP level of theory. Relative $\left(\mathrm{E}_{\text {rel }}\right)$ and binding energies $\left(\mathrm{E}_{\text {bind }}\right)$ are given in kcal.mol ${ }^{-1}$. Important hydrogenbond distances are indicated in bold and are given in $\AA$.

\section{CALCULATED STRUCTURES OF HYDRATED PROTONATED URACIL CLUSTERS - DISCUSSION}

Theoretical works have already been devoted to mixed uracil-water clusters and intended to

describe the lowest-energy structures. However, only neutral species were considered $[14,15,16,17,18,42]$. Those studies showed that for sizes up to $n=3$, the water molecules arrange in monomers or dimers in the plane of the uracil molecule $[15,16,17,18,42]$ with no trimer 
Publishfinghation. For $n>3$, very different structures were predicted depending on the considered study. For instance, Gaigeot et al. [16] predicted that for $n=7$ water molecules arrange in dimers and trimers in the plane of the uracil molecule, whereas for $n=11$ water molecules form locked chains [14]. 3D configurations were also proposed. In that case, all water molecules lie above the uracil plane as reported in [18] for $n=4,5$. Similarly, for $n=11$, Danilov et al. [17] also obtained a structure that consists of a water cluster above the uracil molecule. Such structures are predicted to start with 4 water molecules according to [18] or with 6 water molecules (though 5 has not been calculated) for [15]. Those studies may suggest that, within the frame of the present work, for few water molecules (up to two) the proton should be located on the uracil molecule, whereas when a large number of water molecules surrounds the uracil, the charge is expected to be located on the water molecules. Of course, the excess proton is expected to strongly influence the structure of the lowest-energy isomers of each species, as observed for pure water clusters for instance, so the size at which the proton is transferred from uracil to water cannot be deduced from the aforementioned studies. Moreover, all those theoretical works do not lead to the same low-energy structures as highlighted in [17] and [18]. Consequently, although instructive from a qualitative point of view, the analysis of our experimental data cannot be based on those studies. We have therefore undertaken a theoretical simulation of small hydrated protonated uracil clusters.

The lowest-energy isomers determined theoretically for hydrated uracil protonated clusters $\mathrm{U}\left(\mathrm{H}_{2} \mathrm{O}\right) \mathrm{nH}^{+}$are shown in Figure 8 to Figure 11. In the experiments, clusters are produced at a temperature of about $25 \mathrm{~K}$, so only a very few isomers are likely to be populated. Indeed, the clusters are produced in the canonical ensemble at the temperature $\mathrm{Tc} \approx 25 \mathrm{~K}$, so only isomers for which the Boltzmann factor $\exp (-\Delta \mathrm{E} / \mathrm{kBTc})$ is larger than $\sim 10^{-7}$ are considered here. In this formula, $\Delta \mathrm{E}$ represents the relative energy of a considered isomer with respect to the lowest-energy 
Publishaingrg For each isomer, we thus only discuss the 3 (6 for $\mathrm{U}\left(\mathrm{H}_{2} \mathrm{O}\right) \mathrm{H}^{+}$) lowest-energy structures obtained from the PES exploration. Additional isomers are reported in the Supplementary Material.

Figure 8 displays the six lowest-energy isomers obtained for $\mathrm{U}\left(\mathrm{H}_{2} \mathrm{O}\right) \mathrm{H}^{+}$. Two (1a and $\left.1 \mathrm{~b}\right)$ of them contain the u138-like isomer of $U$ (each one with a different orientation of the hydroxyl hydrogen), 3 of them (1c, 1d and 1e) the u178 isomer and $1 \mathrm{f}$ contains the u137 isomer with a reverse orientation of the hydroxyl hydrogen. From those 3 isomers, different sites are possible for the water molecule attachment which leads to variety of isomers even for such small size system. To the best of our knowledge, $\mathrm{U}\left(\mathrm{H}_{2} \mathrm{O}\right) \mathrm{H}^{+}$is the most studied protonated uracil water cluster and our results are consistent with previous published works. Indeed, Pedersen and coworkers [31] conducted ultraviolet action spectroscopy on $\mathrm{U}\left(\mathrm{H}_{2} \mathrm{O}\right) \mathrm{H}^{+}$and discussed their measurements in the light of theoretical calculations performed on two isomers: ur138w8 (1a in the present study) and ur178w7 (1c) [31]. Their energy ordering at $0 \mathrm{~K}$ is the same whatever the computational method they used: B3LYP/6-311++G(3df,2p), M06-2X/6-311++G(3df,2p), MP2/6-311++G(3df,2p), $\operatorname{CCSD}(\mathrm{T}) / 6-311++\mathrm{G}(3 \mathrm{df}, 2 \mathrm{p})$ and $\operatorname{CCSD}(\mathrm{T}) /$ aug-cc-pVTZ and is similar to what we obtain. Similarly, Bakker and coworkers [13] considered three isomers: $\mathrm{U}(\mathrm{DK}) \mathrm{H}^{+}{ }_{-} \mathrm{W}(1 \mathrm{a}), \mathrm{U}(\mathrm{KE}) \mathrm{H}^{+}{ }_{-} \mathrm{Wa}$ (1c) and $\mathrm{U}(\mathrm{KE}) \mathrm{H}^{+} \mathrm{Wb}(1 \mathrm{e})$ at the B3LYP/6-311++G(3df,2p) level of theory and obtained the same energy ordering as we do. Our methodology has thus allowed us to retrieve those isomers and to locate two new low-energy structures ( $1 \mathrm{~b}$ and $1 \mathrm{~d}), 1 \mathrm{f}$ is too high in energy to be considered in lowtemperature experiments, that are in the same range of relative energies but have never been discussed. To ensure that they are not artificially favored in our computational method, calculations were also performed at the B3LYP/6-311++G(3df,2p) level of theory. The results are presented in the Supplementary Material and are consistent with the MP2/Def2TZVP ones. This makes us confident in the ability of the present methodology to locate meaningful low energy structures. 
Publishingortantly, no isomer with the proton on the water molecule was obtained, neither at the DFTB or MP2 levels.

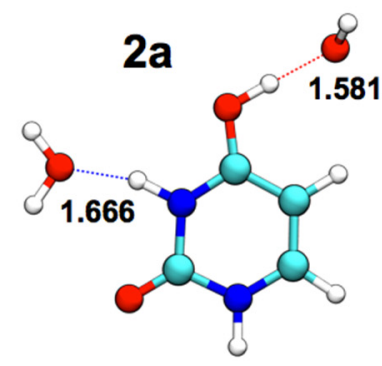

Erel $\quad 0.0$

E $\quad-38.2$
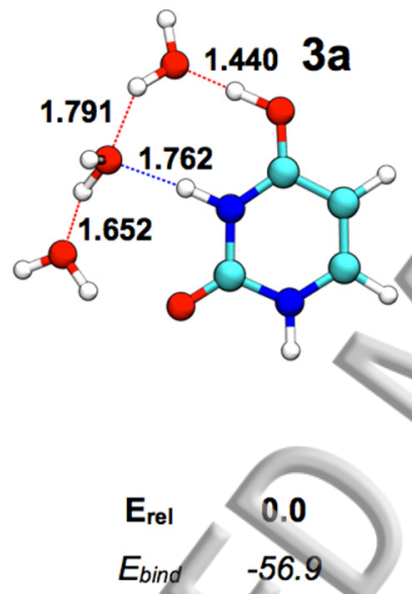

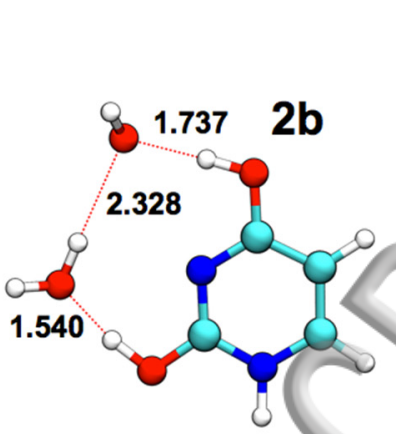

Erel

$E_{\text {bind }}$

0.2

$-35.5$

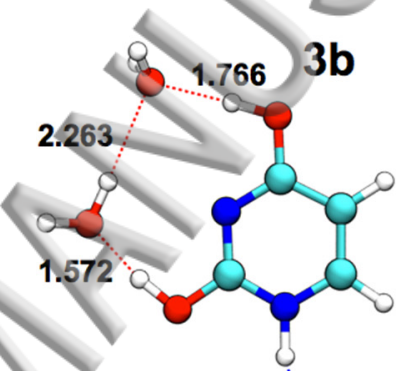

1.716

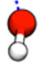

Erel

$E_{\text {bind }}$
0.3

$-51.2$
$1.4932 \mathrm{C}$

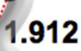

881

881

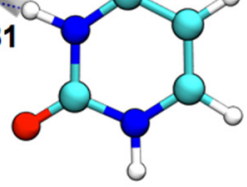

Erel $\quad 0.3$

Ebind $\quad-40.9$
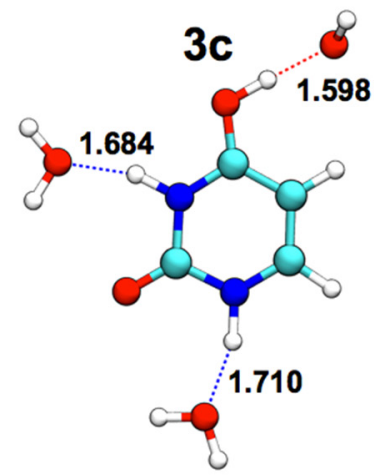

Erel $\quad 1.0$

$E_{\text {bind }} \quad-52.9$

Figure 9: The three lowest-energy structures of $\mathrm{U}\left(\mathrm{H}_{2} \mathrm{O}\right)_{2} \mathrm{H}^{+}$(top) and $\mathrm{U}\left(\mathrm{H}_{2} \mathrm{O}\right)_{3} \mathrm{H}^{+}$ (bottom) obtained at the MP2/Def2TZVP level of theory. Relative ( $\left.\mathrm{E}_{\text {rel }}\right)$ and binding energies ( $\left.\mathrm{E}_{\text {bind }}\right)$ are given in kcal.mol-1 . Important hydrogen-bond distances are indicated in bold and are given in $\AA$.

Figure 9 displays the three lowest-energy isomers obtained for $\mathrm{U}\left(\mathrm{H}_{2} \mathrm{O}\right)_{2} \mathrm{H}^{+}$and $\mathrm{U}\left(\mathrm{H}_{2} \mathrm{O}\right)_{3} \mathrm{H}^{+}$. For $\mathrm{U}\left(\mathrm{H}_{2} \mathrm{O}\right)_{2} \mathrm{H}^{+}$, the lowest energy structure contains the u138 isomer of uracil while $2 \mathrm{~b}$ and $2 \mathrm{c}$ contain u178 and u138 with reverse orientation of the hydroxyl hydrogen, respectively. This 
Publishdingonstrates that, similarly to $\mathrm{U}\left(\mathrm{H}_{2} \mathrm{O}\right) \mathrm{H}^{+}$, a diversity of uracil isomers are present in the lowenergy structures of $\mathrm{U}\left(\mathrm{H}_{2} \mathrm{O}\right)_{2} \mathrm{H}^{+}$which makes an exhaustive exploration of its PES all the more difficult. The same behavior is observed for $\mathrm{U}\left(\mathrm{H}_{2} \mathrm{O}\right)_{3} \mathrm{H}^{+}$. The configuration of $\mathrm{u} 138$ does not allow for the formation of a water dimer which leads to two unbound water molecules in $2 \mathrm{a}$. In contrast, a water-water hydrogen bond is observed for $2 b$ and $2 c$. The existence of a water dimer was not encountered in the low-energy isomers of the unprotonated $\mathrm{U}\left(\mathrm{H}_{2} \mathrm{O}\right)_{2}$ species due to the absence of hydroxyl group on $\mathrm{U}$. It is worth pointing out that $2 \mathrm{a}, 2 \mathrm{~b}$ and $2 \mathrm{c}$ are very close in energy which makes their exact energy ordering difficult to determine. However, no isomer displaying an unprotonated uracil (cf. Supplementary Material for additional $\mathrm{U}\left(\mathrm{H}_{2} \mathrm{O}\right)_{2} \mathrm{H}^{+}$low-energy isomers) was located. The lowest-energy structure of $\mathrm{U}\left(\mathrm{H}_{2} \mathrm{O}\right)_{3} \mathrm{H}^{+}$is characterized by two water-water hydrogen bond that forms a linear water trimer. Higher energy isomers display only one (3b) or zero (3c) water-water bond (cf. Supplementary Material for additional $\mathrm{U}\left(\mathrm{H}_{2} \mathrm{O}\right)_{3} \mathrm{H}^{+}$low-energy isomers). Isomer $3 \mathrm{~b}$ is similar to $2 \mathrm{~b}$ with an isolated water molecule linked to the protonated nitrogen of $\mathrm{U}$. Similarly to $\mathrm{U}\left(\mathrm{H}_{2} \mathrm{O}\right)_{2} \mathrm{H}^{+}$, no isomer displaying an unprotonated uracil was located for $\mathrm{U}\left(\mathrm{H}_{2} \mathrm{O}\right)_{3} \mathrm{H}^{+}$.

Figure 10 displays the three lowest-energy isomers obtained for $\mathrm{U}\left(\mathrm{H}_{2} \mathrm{O}\right)_{4} \mathrm{H}^{+}$and $\mathrm{U}_{(}\left(\mathrm{H}_{2} \mathrm{O}\right)_{5} \mathrm{H}^{+}$ which constitute a transition in the behavior of the proton. Indeed, in $\mathrm{U}\left(\mathrm{H}_{2} \mathrm{O}\right)_{4} \mathrm{H}^{+}$, two kind of lowenergy structures appear: (i) structures composed of $\mathrm{UH}^{+}$, one water trimer and one isolated water molecule (4b); (ii) structures composed of $U$ and a protonated water tetramer (4a and $4 c)$. In the latter case, the hydronium ion is always bounded to an uracil oxygen atom. This $\mathrm{U}-\mathrm{H}_{3} \mathrm{O}^{+}$bond is always rather strong as compared to $\mathrm{U}-\mathrm{H}_{2} \mathrm{O}$ bonds as highlighted by the corresponding short oxygen-hydrogen distance. Furthermore, speaking of distances, the difference between the $\mathrm{U}_{-} \mathrm{H}_{3} \mathrm{O}^{+}$ and $\mathrm{UH}^{+}-\mathrm{H}_{2} \mathrm{O}$ forms is rather fuzzy and might be sensitive to computational parameters and also to 
Publishingrn um fluctuations of the hydrogen. This suggests that collision with $\mathrm{U}\left(\mathrm{H}_{2} \mathrm{O}\right)_{4} \mathrm{H}^{+}$is more likely to induce evaporation of $\mathrm{H}_{2} \mathrm{O}$ rather than $\mathrm{H}_{3} \mathrm{O}^{+}$or a protonated water cluster. The picture is significantly different in $\mathrm{U}\left(\mathrm{H}_{2} \mathrm{O}\right)_{5} \mathrm{H}^{+}$where the lowest-energy structure displays a hydronium ion separated by one water molecule from $\mathrm{U}$. Such structures do not appear in $\mathrm{U}\left(\mathrm{H}_{2} \mathrm{O}\right)_{4} \mathrm{H}^{+}$due to the limited number of water molecules available to separate $\mathrm{H}_{3} \mathrm{O}^{+}$from $\mathrm{O}$. Such separation suggests that, if considering a direct dissociation process, evaporation of neutral uracil can now occurs in agreement with the experimental observations (see discussion above). One sees that $5 \mathrm{~b}$, which is only $0.3 \mathrm{kcal}^{\mathrm{mol}} \mathrm{l}^{-1}$ higher in energy than $5 \mathrm{a}$, still displays a $\mathrm{U}-\mathrm{H}_{3} \mathrm{O}^{+}$link. This is in line with the low amount of neutral uracil that is evaporated in the experiment (see Figure 6). 

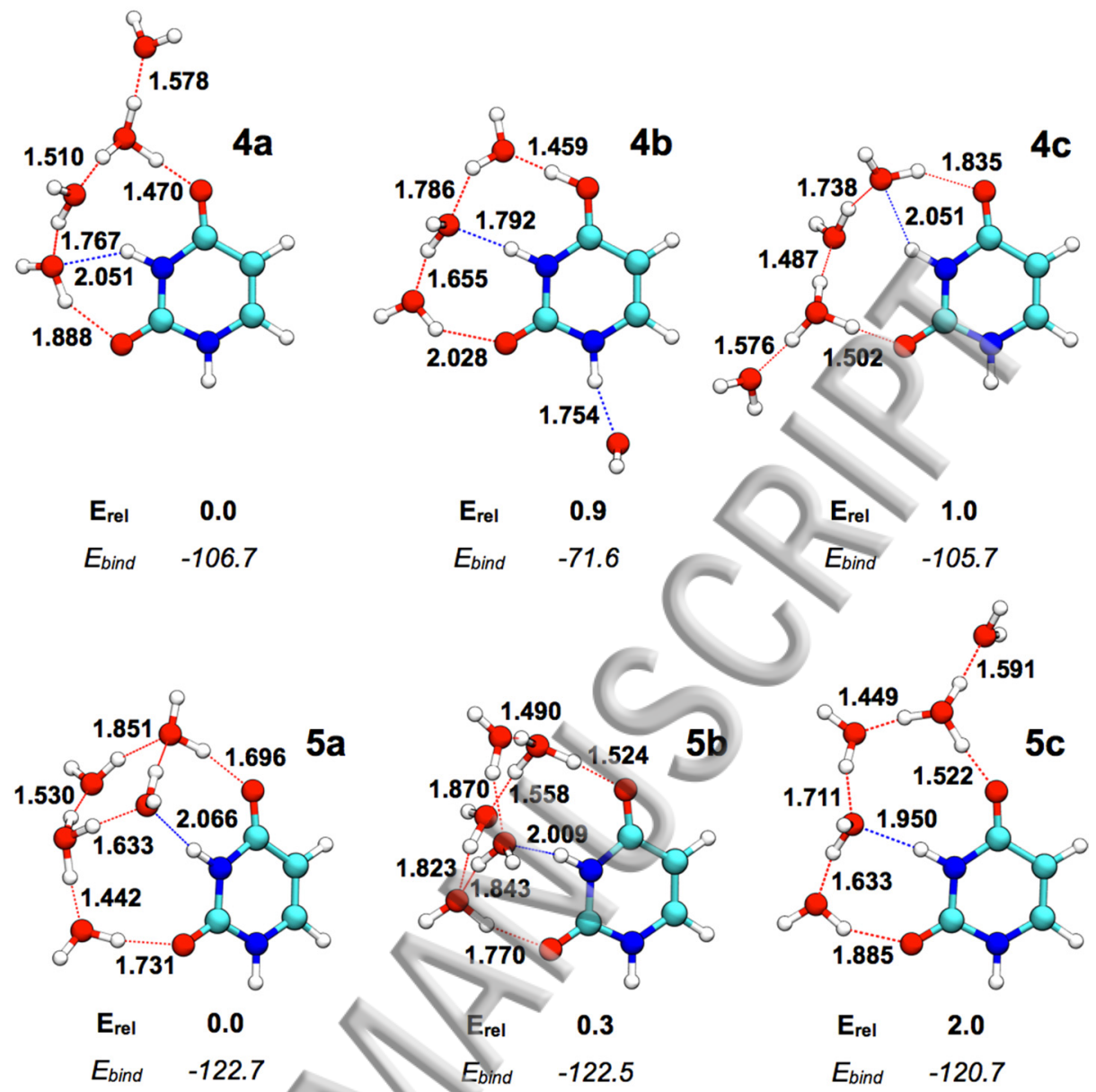

Figure 10: The three lowest-energy structures of $\mathrm{U}\left(\mathrm{H}_{2} \mathrm{O}\right)_{4} \mathrm{H}^{+}$(top) and $\mathrm{U}\left(\mathrm{H}_{2} \mathrm{O}\right)_{5} \mathrm{H}^{+}$(bottom) obtained at the MP2/Def2TZVP level of theory. Relative (Erel) and binding energies ( $\mathrm{E}_{\text {bind }}$ ) are given in $\mathrm{kcal}^{\mathrm{mol}}{ }^{-1}$. Important hydrogen-bond distances are indicated in bold and are given in $\AA$.

Finally, Figure 11 displays the three lowest-energy isomers obtained for $\mathrm{U}\left(\mathrm{H}_{2} \mathrm{O}\right)_{6} \mathrm{H}^{+}$and $\mathrm{U}\left(\mathrm{H}_{2} \mathrm{O}\right)_{7} \mathrm{H}^{+}$. Similarly to $\mathrm{U}\left(\mathrm{H}_{2} \mathrm{O}\right)_{5} \mathrm{H}^{+}$, the lowest-energy structure we located for both species has the excess proton on a water molecule that is separated by one water molecule from the uracil. This appears to be common to the clusters with at least 5 water molecules. This is also observed for higher-energy isomers $(6 \mathrm{c}, 7 \mathrm{c})$ although other characteristics of the proton are observed: proton in a very symmetrical Zundel form bounded to the uracil (6b) or $\mathrm{H}_{3} \mathrm{O}^{+}$still bounded to uracil (7b). Of course, for $\mathrm{U}\left(\mathrm{H}_{2} \mathrm{O}\right)_{6} \mathrm{H}^{+}$and $\mathrm{U}\left(\mathrm{H}_{2} \mathrm{O}\right)_{7} \mathrm{H}^{+}$and also $\mathrm{U}\left(\mathrm{H}_{2} \mathrm{O}\right)_{6} \mathrm{H}^{+}$and $\mathrm{U}\left(\mathrm{H}_{2} \mathrm{O}\right)_{5} \mathrm{H}^{+}$, the amount of low- 
Publisheinggg isomers is expected to be very large and we do not intended to find them all. Furthermore, due to the limited number of MP2 geometry optimization we performed there is few chances that we located the global energy minima for $\mathrm{U}\left(\mathrm{H}_{2} \mathrm{O}\right)_{6} \mathrm{H}^{+}$and $\mathrm{U}\left(\mathrm{H}_{2} \mathrm{O}\right)_{7} \mathrm{H}^{+}$. However, the general picture we are able to draw from the presently discussed structures fully support the experimental results: from $\mathrm{U}\left(\mathrm{H}_{2} \mathrm{O}\right)_{5} \mathrm{H}^{+}$, it exists low-energy structures populated at very low temperature in which the excess proton is not directly bound to the uracil molecule. Upon fragmentation, this allows the proton to remain bounded to the water molecules.

All the aforementioned low-energy structures are relevant to describe the $\mathrm{U}\left(\mathrm{H}_{2} \mathrm{O}\right)_{\mathrm{n}=1-7} \mathrm{H}^{+}$ species at low temperature and to understand the relation between the parent cluster size and the amount of evaporated neutral uracil in the case of direct dissociation. However, as already stated, one has to keep in mind that upon collision statistical dissociation can also occur. In that case structural rearrangements are expected to occur. which are important to understand each individual mass spectra of the $\left(\mathrm{H}_{2} \mathrm{O}\right)_{\mathrm{n}=1-15} \mathrm{H}^{+}$clusters and the origin of each collision product.

For instance, the fragment $\mathrm{UH}^{+}$is detected for all cluster sizes (see Figure 1 and time of flight mass spectra presented in the Supplementary Material). This means that for the largest sizes, for which we have shown from the calculation that the proton is located away from the uracil, proton transfer does occur prior to dissociation. One possible scenario is that after collision, water molecules sequentially evaporates. When the number of water molecules is small enough the proton affinity of uracil gets larger than the one of the remaining attached water cluster. Proton transfer is then likely and we therefore end up with protonated uracil.

If one now turns to the neutral uracil evaporation channel it appears that the smaller clusters $\mathrm{H}_{3} \mathrm{O}^{+}$and $\left(\mathrm{H}_{2} \mathrm{O}\right)_{2} \mathrm{H}^{+}$are not present in the time of flight mass spectra. This absence might have two 


\section{This manuscript was accepted by J. Chem. Phys. Click here to see the version of record.}

Publishinigins. First, the dissociation energies of the protonated water dimers and trimers are substantially higher than larger sizes, and they are therefore less prone to evaporation. Second, as already mentioned, for such small sizes, the proton affinity of uracil gets larger than the one of the water dimer or trimer and proton transfer to the uracil is likely to occur.

In order to confirm the above scenario, simulations and/or evaporation rates calculation would have to be conducted to describe the fragmentation channels in details. Such molecular dynamics simulations have already been performed by Spezia and coworkers to understand the collisional induced dissociation of various organic molecules $[9,10,43,44]$. Although in the present case the initial position of the excess proton appears as a key parameter to explain the evaporation of neutral uracil, such simulations could be additionally conducted to provide a clearer picture on the various evaporation pathways. 


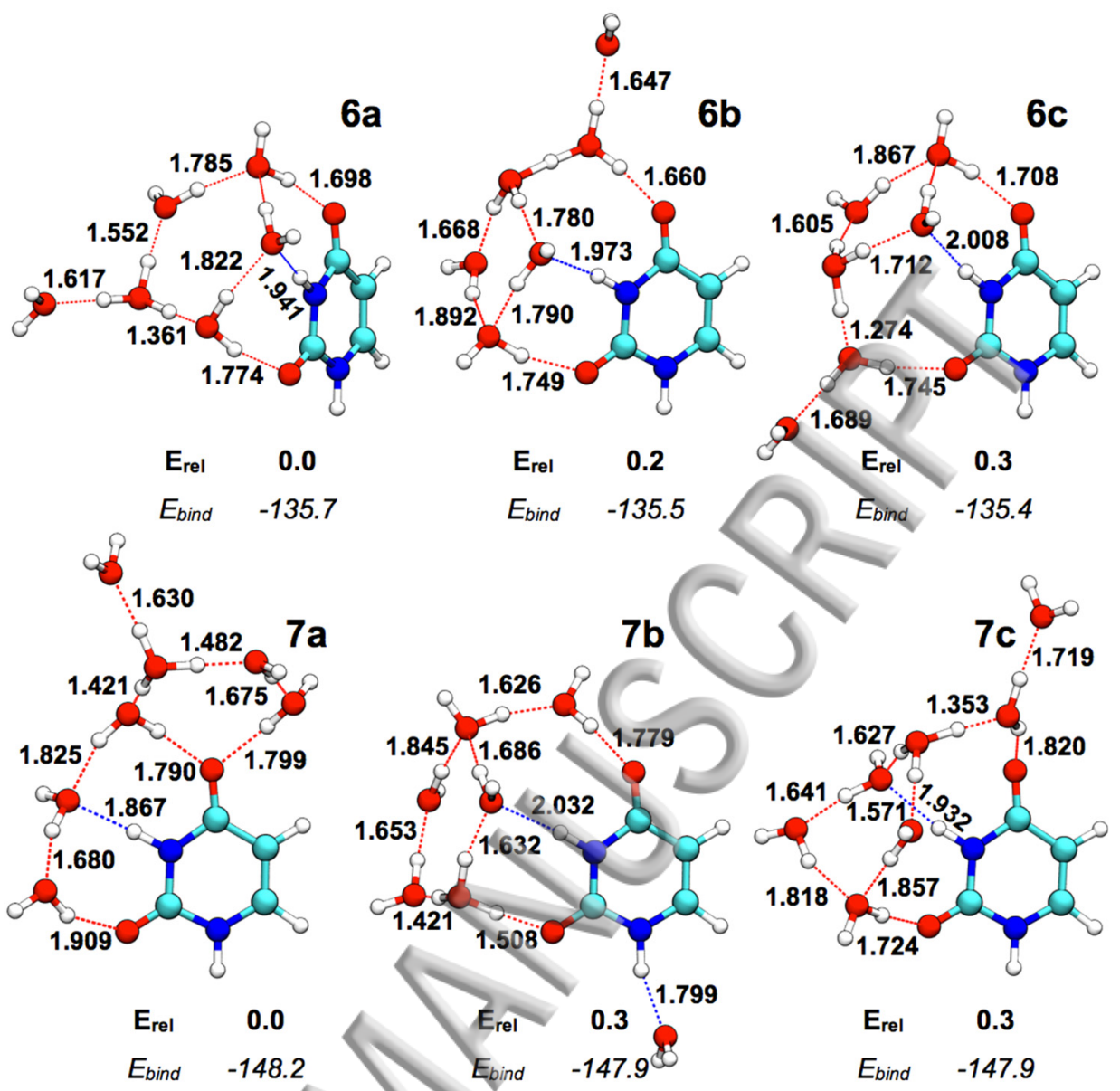

Figure 11: The three lowest-energy structures of $\mathrm{U}\left(\mathrm{H}_{2} \mathrm{O}\right)_{6} \mathrm{H}^{+}$(top) and $\mathrm{U}\left(\mathrm{H}_{2} \mathrm{O}\right)_{7} \mathrm{H}^{+}$ (bottom) obtained at the MP2/Def2TZVP level of theory. Relative ( $\left.\mathrm{E}_{\text {rel }}\right)$ and binding energies ( $\left.\mathrm{E}_{\text {bind }}\right)$ are given in kcal.mol ${ }^{-1}$. Important hydrogen-bond distances are indicated in bold and are given in $\AA$.

\section{CONCLUSION}

This article presents the collision induced dissociation of hydrated protonated uracil $\mathrm{U}\left(\mathrm{H}_{2} \mathrm{O}\right)_{\mathrm{n}=1 \text { - }}$ ${ }_{15} \mathrm{H}^{+}$clusters and reports their experimental absolute fragmentation cross sections. We demonstrate that the evaporation channels evolve with size: Below $n=5$, the observed charged fragments always contain the uracil molecule, whereas from $n=5$ the loss of a neutral uracil molecule becomes significant. To understand this transition, we conducted an exploration of the potential energy 
Publishsingace of $\mathrm{U}\left(\mathrm{H}_{2} \mathrm{O}\right)_{\mathrm{n}=1-7} \mathrm{H}^{+}$clusters combining a rough exploration at the DFTB level with fine geometry optimizations at the MP2 level of theory. Those calculations show that below $n=5$, the excess proton is either on the uracil or on a water molecule directly bound to uracil, i.e. forming a strongly bound $\mathrm{U}-\mathrm{H}_{3} \mathrm{O}^{+}$complex. From $n=5$ and above, clusters contain enough water molecules to allow for a net separation between uracil and the excess proton: The latter is often found bound to a water molecule which is separated from uracil by at least one other water molecule. Upon direct dissociation, the excess proton and the uracil can thus belong to different fragments.

This study demonstrates that combination of collision induced dissociation experiments and theoretical calculation allow to probe the solvation and protonation properties of organic molecules such as nucleobases. This is a step towards a better understanding of the role of water in the chemistry of in vivo DNA and RNA bases.

\section{SUPPLEMENTARY MATERIAL}

Figure S1 of the Supplementary Material reports the $\mathrm{U}(\mathrm{H} 2 \mathrm{O}) \mathrm{H}+$ lowest-energy structures obtained at the B3LYP/6-311++G(3df,2p) level of theory.

Additional lowest-energy structures of $\mathrm{U}\left(\mathrm{H}_{2} \mathrm{O}\right)_{\mathrm{n}=2-7} \mathrm{H}^{+}$obtained at the MP2/Def2TZVP level of theory are presented in Figures S2 to S7.

Figures S8 to S20 present the experimental time of flight mass spectra such as the one presented in figure 1 for sizes $\left(\mathrm{H}_{2} \mathrm{O}\right)_{\mathrm{n}=1-12} \mathrm{UH}^{+}$and $\left(\mathrm{H}_{2} \mathrm{O}\right)_{\mathrm{n}=15} \mathrm{UH}^{+}$.

An xyz coordinates file is also provided with all the calculated structures. The structure of the file is the following: 
$<$ Isomer number, as in the figures of the paper $>E=<$ energy in Hartree $>$

$<$ Element $1><\mathrm{x}(1)><\mathrm{y}(1)><\mathrm{z}(1)>$

$<$ Element $2><\mathrm{x}(2)><\mathrm{y}(2)><\mathrm{z}(2)>$

$<$ Element $\mathrm{n}><\mathrm{x}(\mathrm{n})><\mathrm{y}(\mathrm{n})><\mathrm{z}(\mathrm{n})>$

\section{ACKNOWLEDGEMENT}

This work has been partly funded by the Agence Nationale de la Recherche (ANR) under Grant No. ANR-11-BS04-0028. 
${ }^{1}$ Wincel H., J. Am. Soc. Mass Spectrom. , 20, 1900-1905 (2009)

${ }^{2}$ Boudaiffa B., Cloutier P., Hunting D., Huels M. A. and Sanche L., Science 287, 1658-1660 (2000)

${ }^{3}$ Ptasińska S. and Sanche L., Phys. Rev. E 75, 031915 (2007)

${ }^{4}$ Smyth M. and Kohanoff J., Phys. Rev. Lett. 106, 238108 (2011)

${ }^{5}$ Siefermann K. R. and Abel B., Angew. Chem., Int. Ed. 50, 5264-5272 (2011)

${ }^{6}$ Alizadeh E., Sanz A. G., García G., and Sanche L., J. Phys. Chem. Lett. 4, 820-825 (2013)

${ }^{7}$ Hayes R. N. and Gross M. L. In [10] Collision-induced dissociation; Enzymology, B.M. i., Ed.; Mass Spectrometry; Academic Press, 1990; Vol. 193; pp 237-263

${ }^{8}$ Nelson C. C. and McCloskey J. A., J. Am. Soc. Mass Spectrom. 5, 339-349, (1994).

9 Molina E. R., Ortiz D., Salpin J.-Y. and Spezia R., J. Mass Spectrom. 50, 1340- 1351 (2015).

${ }^{10}$ Molina E. R., Salpin J.-Y., Spezia R. and Martinez-Nunez E., Phys. Chem. Chem. Phys. 18, 14980-14990 (2016).

${ }^{11}$ Beach D. G. and Gabryelski W. J., Am. Soc. Mass Spectrom. 23, 858-868 (2012).

${ }^{12}$ Sadr-Arani L., Mignon P., Chermette H. and Douki T., Chem. Phys. Lett. 605606, 108-114 (2014).

${ }^{13}$ Bakker J. M., Sinha R. K., Besson T., Brugnara M., Tosi P., Salpin J.-Y. and Maître P., J. Phys. Chem. A 112, $12393-12400$ (2008).

${ }^{14}$ Shishkin O. V., Gorb L. and Leszczynski J., Int. J. Mol. Sci. 1, 17-27 (2000).

${ }^{15}$ Gadre S. R., Babu K. and Rendell A. P., J. Phys. Chem. A 104, 8976-8982 (2000).

${ }^{16}$ Gaigeot M.-P. and Ghomi M., J. Phys. Chem. B 105, 5007-5017 (2001).

${ }^{17}$ Danilov V. I., van Mourik T. and Poltev V. I., Chem. Phys. Lett. 429, 255-260 (2006).

${ }^{18}$ Bacchus-Montabonel M.-C. and Calvo F., Phys. Chem. Chem. Phys. 17, 9629-9633 (2015).

${ }^{19}$ Chirot F., Zamith S., Labastie P. and L’Hermite J.-M., Rev. Sci. Instrum. 77, 063108 (2006).

${ }^{20}$ Braud I., Zamith S. and L’Hermite J.-M., Rev. Sci. Instrum. 88, 043102 (2017).

${ }^{21}$ Brunetti B, Piacente V. and Portalone G. J., Chem. Eng. Data 45, 242-246 (2000).

${ }^{22}$ Puzzarini C., Biczysko M. and Barone V., Journal of Chemical Theory and Computation 7, 3702-3710 (2011).

${ }^{23}$ Sugita Y. and Okamoto Y., Chem. Phys. Lett. 314, 141-151 (1999) Sugita Y. and Okamoto Y., Chem. Phys. Lett. 329, 261-270 ( 2000) Earl D. J. and Deem M. W., Phys. Chem. Chem. Phys. 7, 3910-3916 (2005). 
7260-7268 (1998) Frauenheim T., Seifert G., Elsterner M., Hajnal Z., Jungnickel G., Porezag D., Suhai S. and Scholz

R., Phys. Status Solidi B 217, 41-62 (2000).

${ }^{25}$ Nosé S. A., J. Chem. Phys. 81, 511-519 (1984) Hoover W. G., Phys. Rev. A 31, 1695-1697 (1985).

${ }^{26}$ Elstner M., Porezag D., Jungnickel G., Elsner J., Haugk M., Frauenheim T., Suhai S. and Seifert G., Phys. Rev. B 58, 7260-7268 (1998).

${ }^{27}$ Thompson J. D., Cramer C. J. and Truhlar D. G., J. Comput. Chem. 24, 1291 -1304 (2003) Winget P., Thompson J. D.; Xidos J. D., Cramer C. J. and Truhlar D. G., J. Phys. Chem. A 106, 10707-10717 (2002).

${ }^{28}$ Rapacioli M., Spiegelman F., Talbi D., Mineva T., Goursot A., Heine T. and Seifert G., J. Chem. Phys. 130, 244304 (2009).

${ }^{29}$ Simon A., Rapacioli M., Mascetti J. and Spiegelman F , Phys. Chem. Chem. Phys. 14, 6771-6786 (2012).

${ }^{30}$ Heine T., Rapacioli M., Patchkovskii S., Frenzel J., Koster A., Calaminici P., Duarte H., Escalante S., Flores-Moreno R., Goursot A. et al. deMonNano. http://demon-nano.ups-tlse.fr/.

${ }^{31}$ Pedersen S. O., Byskov C. S., Turecek F. and Nielsen S. B., J. Phys. Chem. A 118, 4256-4265 (2014).

32 Weigend F. and Ahlrichs R., Phys. Chem. Chem. Phys. 7, 3297-305 (2005).

${ }^{33}$ Weigend F., Phys. Chem. Chem. Phys. 8, 1057-65 (2006).

${ }^{34}$ Frisch M. J., Trucks G. W., SchlegelH. B., Scuseria G. E., Robb M. A., Cheeseman J. R., Scalmani G., Barone V., Mennucci B., Petersson G. A. et al. Gaussian 09, revision D.01; Gaussian Inc.: Wallingford, CT, 2009.

${ }^{35}$ Dalleska N. F., Honma K. and Armentrout P. B., J. Am. Chem. Soc. 115, 12125- 12131 (1993).

${ }^{36}$ Zamith S., Labastie P. and L'Hermite J.-M., J. Chem. Phys. 136, 214301(2012).

${ }^{37}$ Myers R. L., The 100 Most Important Chemical Compounds, A Reference Guide; Green- woodn Press, 2007.

${ }^{38}$ Hansen K., Andersson P. U. and Uggerud E., J. Chem. Phys. 131, 124303 (2009).

${ }^{39}$ Kurinovitch M. A., Phillips L. M., Sharma S. and Lee J. K., Chem. Commun. 2354-2355 (2002).

${ }^{40}$ Magnera T. F., David D. E. and Michl J., Chem. Phys. Lett. 182, 363-370 (1991).

${ }^{1}$ Cheng H.-P., J. Phys. Chem. A 102, 6201-6204 (1998).

${ }^{42}$ Van Mourik T., Price S. L. and Clary D. C., Faraday Discuss. 118, 95-108 (2001).

${ }^{43}$ Spezia R., Salpin J.-Y., Gaigeot M.-P., Hase W. L., Song, K. J. Phys. Chem. A 113, 13853-13862 (2009) 
Chem. Chem. Phys., 20, 3614 (2018)

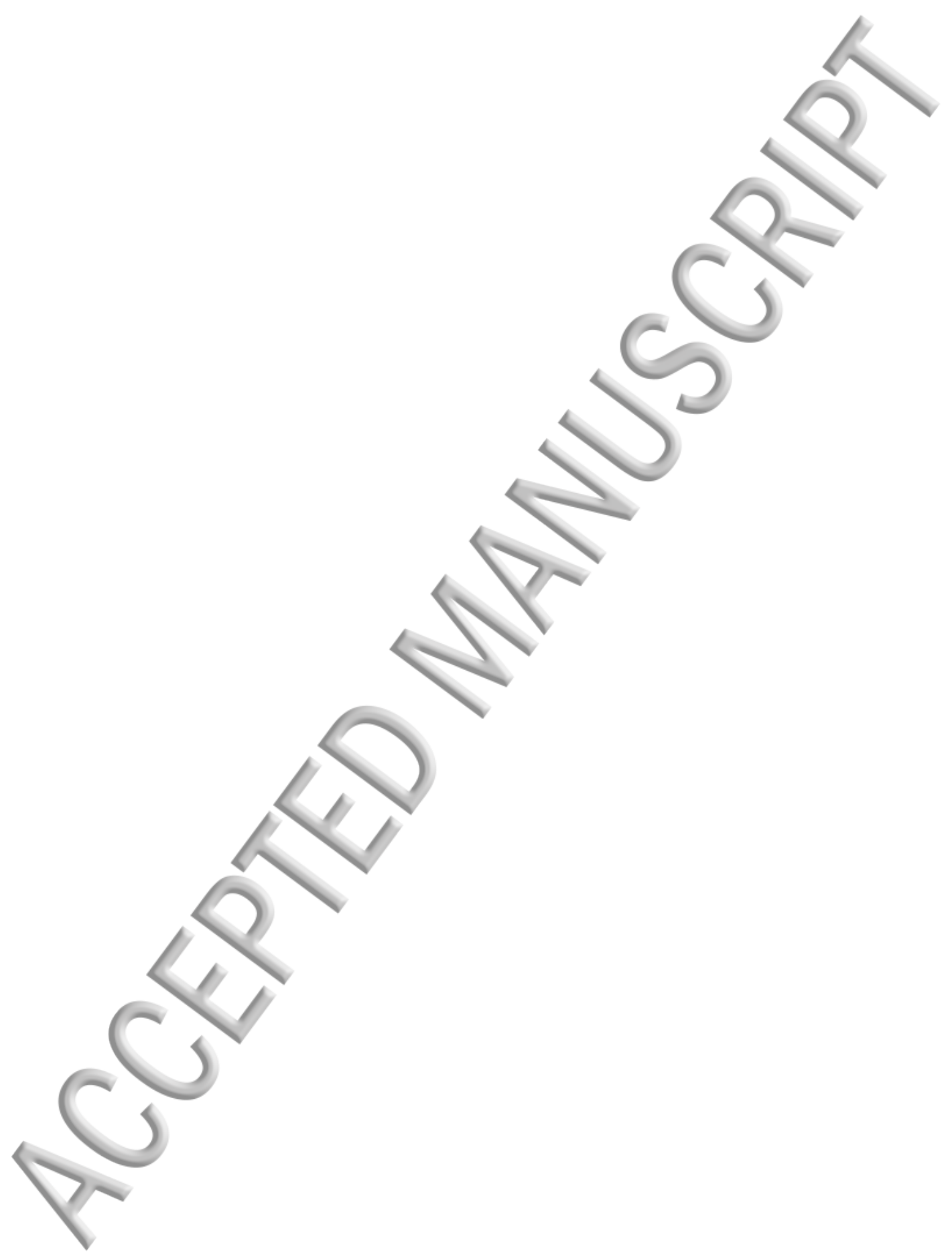




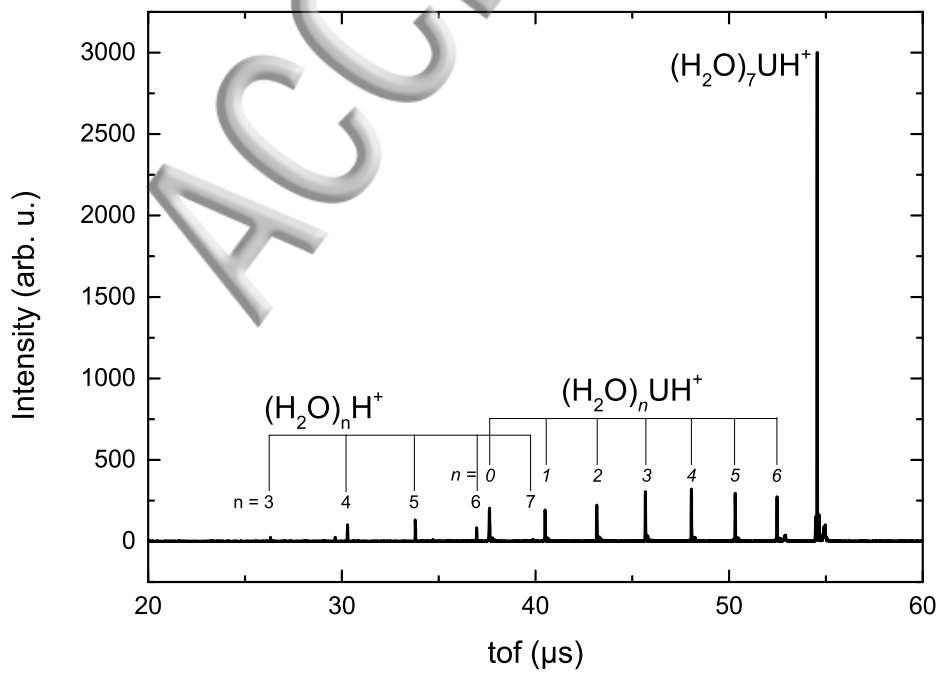




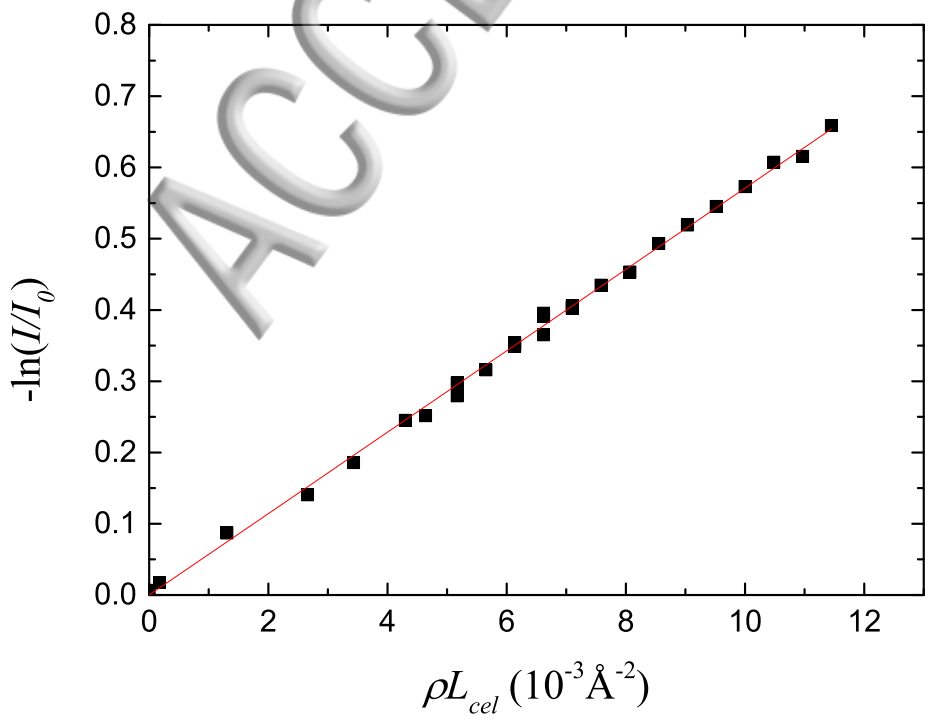




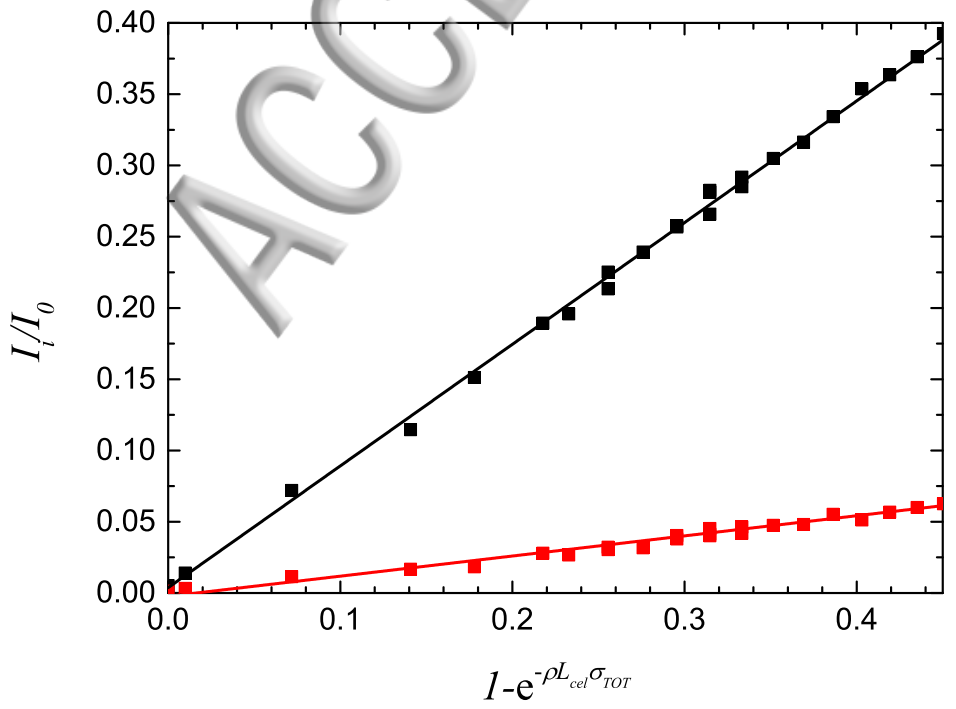




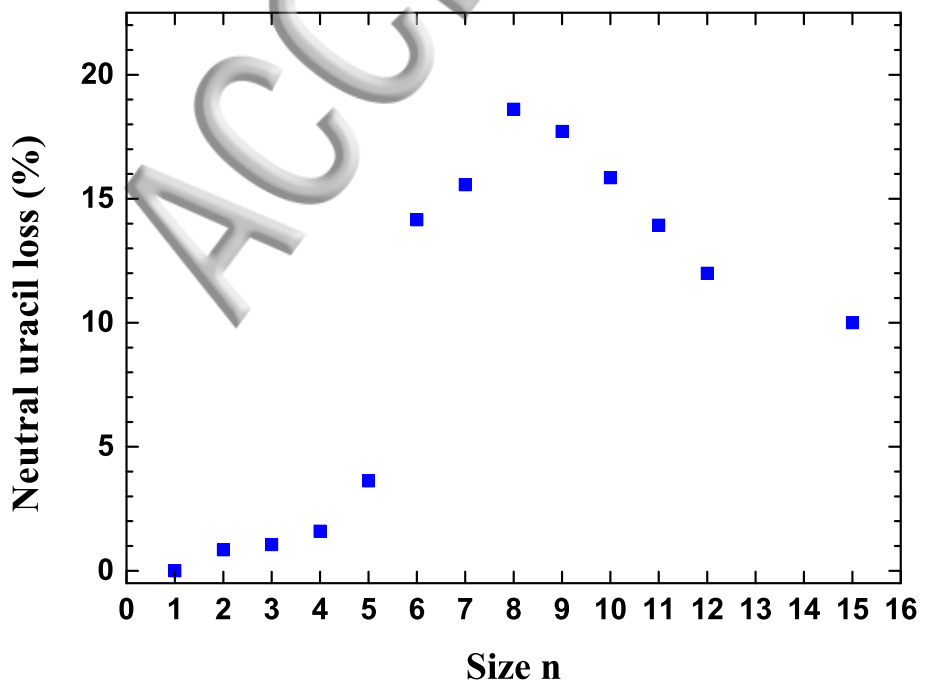




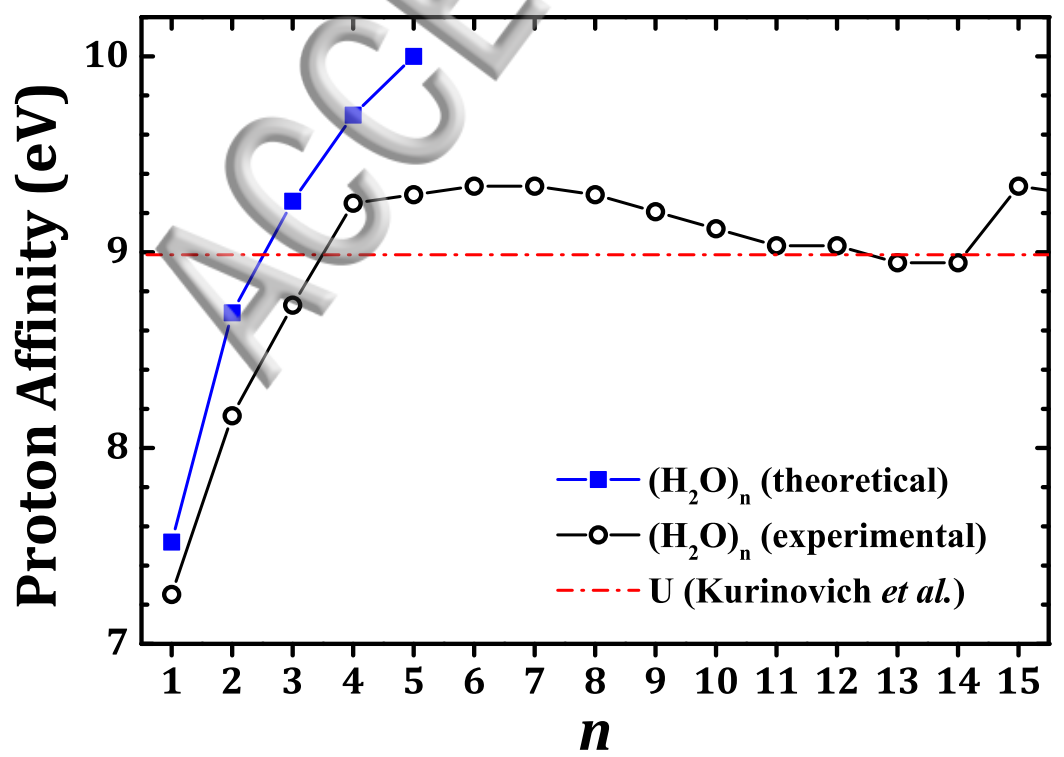




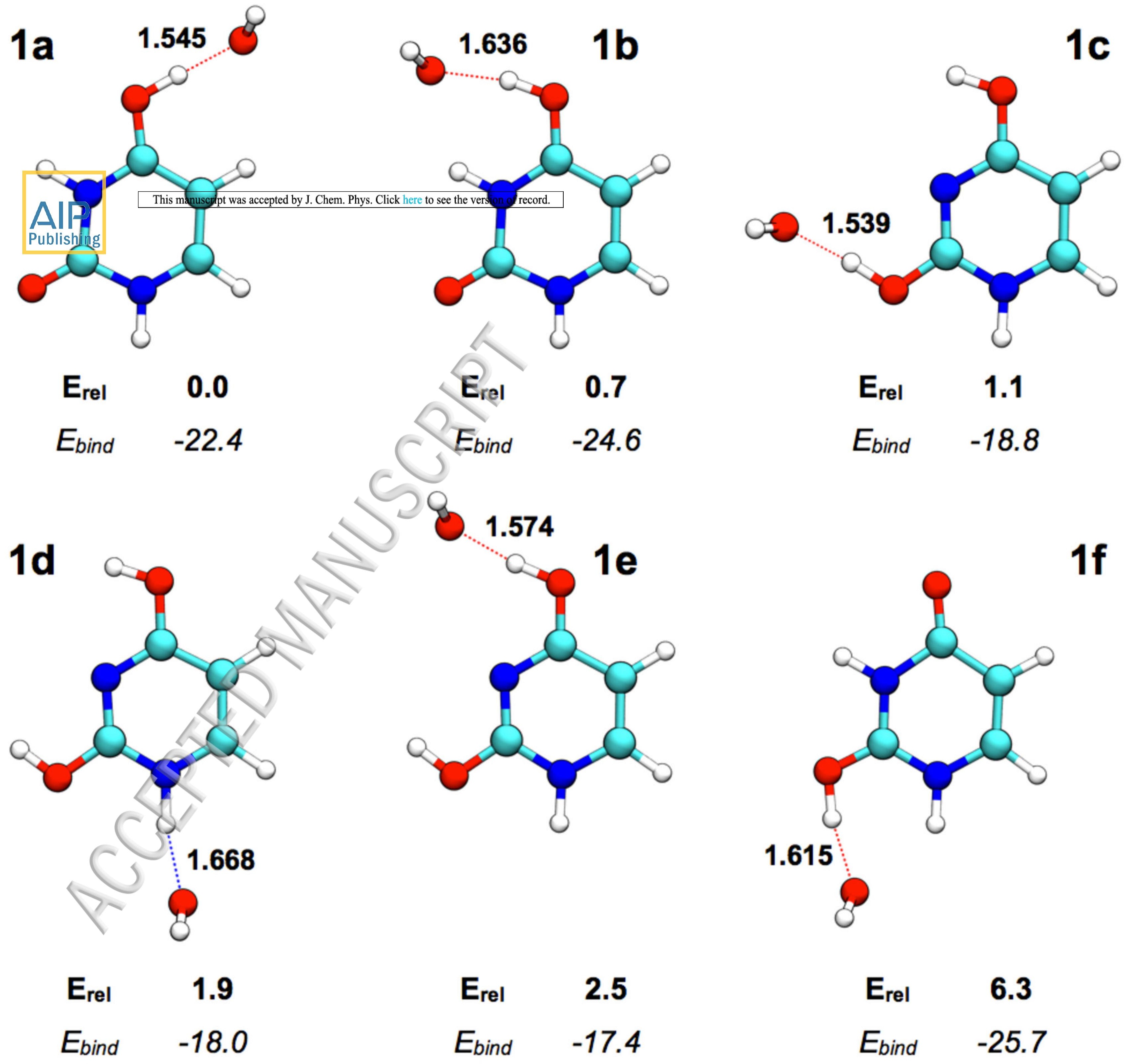




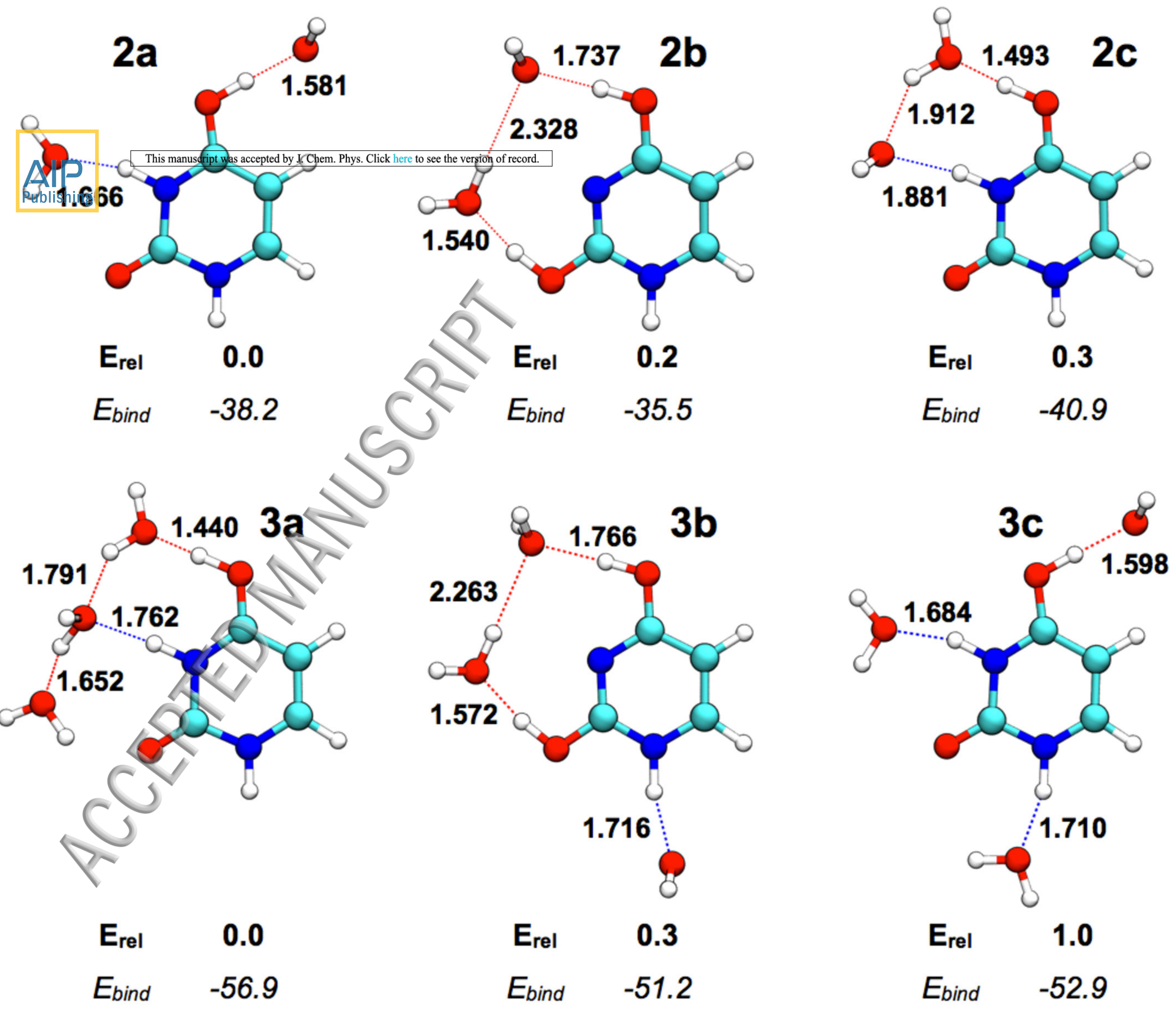




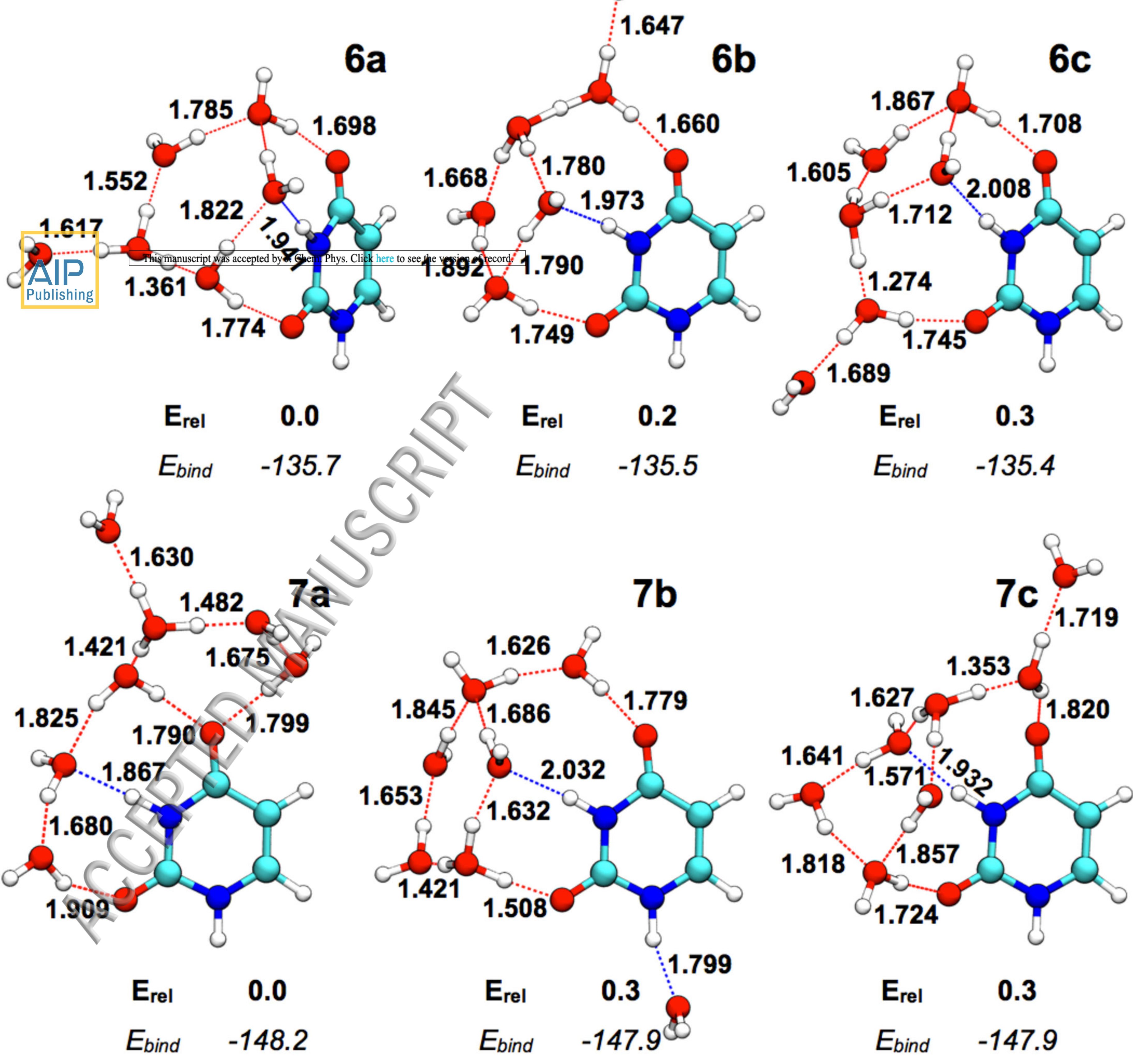

